\title{
Further insights into calcium sulfoaluminate cement expansion
}

\section{Craig W. Hargis}

Assistant Professor, University of North Florida, Jacksonville, FL, USA; Empa, Swiss Federal Laboratories for Materials Science and Technology, Dübendorf, Switzerland

\section{Barbara Lothenbach}

Senior Researcher, Empa, Swiss Federal Laboratories for Materials Science and Technology, Dübendorf, Switzerland; Norwegian University of Science and Technology (NTNU), Department of Structural Engineering, Trondheim, Norway

\author{
Christian J. Müller \\ Project Manager R\&D, Saint-Gobain Weber AG, Winterthur, Switzerland \\ Frank Winnefeld \\ Senior Researcher, Empa, Swiss Federal Laboratories for Materials Science \\ and Technology, Dübendorf, Switzerland (corresponding author: \\ frank.winnefeld@empa.ch) (Orcid:0000-0002-6864-6196)
}

There is still an ongoing debate on the mechanisms of expansion of calcium sulfoaluminate (CSA) cements, which can be either favourable, for example, in shrinkage compensating construction materials, or deleterious in cases of excessive expansion. In order to expand on previous studies, CSA cements with molar ratios (M) of calcium sulfate/ye'elimite of $0.1,1,1.5$ and 2 were investigated from $30 \mathrm{~min}$ to $182 \mathrm{~d}$. All systems showed expansion, and expansion was found to increase with increasing gypsum content. The sample with $M=2$ showed a high expansion and severe cracking after $1 \mathrm{~d}$ of hydration. Based on the pore solution chemistry, crystallisation pressures were calculated, which revealed that not only ettringite, but also the other hydrate phases present (aluminium hydroxide $\left(\mathrm{AH}_{3}\right)$, strätlingite, calcium aluminate decahydrate $\left(\mathrm{CAH}_{10}\right)$, monosulfate) may contribute to the total crystallisation pressure. The percolation pore radii obtained by mercury intrusion porosimetry were used to calculate hydrostatic tensile stresses. It was found that in all investigated systems the hydrostatic tensile stresses exceeded the $1 \mathrm{~d}$ tensile strength, which is in line with the fact that all samples showed expansion.

\section{Notation}

$\begin{array}{ll}A_{y}, B_{y} & \begin{array}{l}P, T \text {-dependent coefficients } \\ a_{i}\end{array} \\ b_{y} & \begin{array}{l}\text { ion-size parameter } \\ \text { semi-empirical parameter }(\sim 0 \cdot 123 \text { for potassium } \\ \left.\text { hydroxide electrolyte at } 25^{\circ} \mathrm{C}\right)\end{array} \\ I & \begin{array}{l}\text { effective molal ionic strength } \\ K_{\mathrm{sp}}\end{array} \quad \begin{array}{l}\text { solubility product of phase } \\ P\end{array} \quad \text { crystallisation pressure } \\ P_{\mathrm{c}} & \text { maximum crystallisation pressure } \\ P_{\mathrm{Hg}} & \text { mercury pressure } \\ R & \text { universal gas constant } \\ r_{\mathrm{c}} & \text { radius of crystal } \\ r_{\mathrm{p}} & \text { pore radius } \\ T & \text { absolute temperature } \\ V_{\mathrm{m}} & \text { molar volume of phase } \\ z_{i} & \text { charge of species } i \\ \gamma_{\mathrm{cl}} & \text { interfacial free energy between crystal and liquid } \\ \gamma_{\mathrm{Hg}} & \text { surface tension } \\ \delta & \text { water layer separating growing crystal and pore wall } \\ \theta_{\mathrm{Hg}} & \text { contact angle } \\ \sigma_{\mathrm{cyl}} & \text { hydrostatic tensile stress for cylindrical geometry } \\ \phi & \text { volume fraction of crystallising phase }\end{array}$

\section{Introduction}

Portland cement (PC) production accounts for approximately $5 \%$ of anthropogenic carbon dioxide $\left(\mathrm{CO}_{2}\right)$ emissions because of its large production quantity and the manufacturing process. Calcium sulfoaluminate (CSA) cements are being researched as potentially more sustainable options that can be added to cement manufacturers' portfolios. CSA cement is regarded as a sustainable cement because it improves upon ordinary PC manufacture in five ways: (a) CSA cement's main early strengthgaining phase is ye'elimite $\left(\mathrm{C}_{4} \mathrm{~A}_{3} \overline{\mathrm{S}}\right)$, which contains only $27.6 \mathrm{wt} \%$ calcium oxide $(\mathrm{CaO})$ compared to PC's main phase, alite $\left(\mathrm{C}_{3} \mathrm{~S}\right)$, which contains $73.7 \%$ calcium oxide; $(b)$ CSA cement can be manufactured at $\sim 150-200^{\circ} \mathrm{C}$ lower temperature than PC; $(c)$ CSA clinker is more friable than PC clinker, making it easier to grind; (d) CSA clinker is blended with relatively high amounts of calcium sulfate to produce CSA cement (Glasser and Zhang, 2001; Mehta, 1980); and (e) CSA can be blended with calcium carbonates or siliceous pozzolans, altering CSA paste's hydration, microstructure and/or other properties (Garcia-Mate et al., 2013; Hargis et al., 2014; Ioannou et al., 2014, 2015; Martin et al., 2015; Pelletier-Chaignat et al., 2012; Zivica, 2000) (cement oxide notation utilised: $\mathrm{A}=$ aluminium oxide $\left(\mathrm{Al}_{2} \mathrm{O}_{3}\right), \mathrm{F}=$ iron (III) oxide $\left(\mathrm{Fe}_{2} \mathrm{O}_{3}\right)$, $\mathrm{T}=$ titanium dioxide $\left(\mathrm{TiO}_{2}\right), \mathrm{S}=$ silicon dioxide $\left(\mathrm{SiO}_{2}\right)$, $\overline{\mathrm{S}}=$ sulfur trioxide $\left(\mathrm{SO}_{3}\right), \mathrm{M}=$ magnesium oxide $(\mathrm{MgO})$, $\mathrm{C}=$ calcium oxide, $\overline{\mathrm{C}}=$ carbon dioxide, $\mathrm{N}=$ sodium oxide $\left(\mathrm{Na}_{2} \mathrm{O}\right), \mathrm{K}=$ potassium oxide $\left(\mathrm{K}_{2} \mathrm{O}\right)$ and $\mathrm{H}=$ water $\left.\left(\mathrm{H}_{2} \mathrm{O}\right)\right)$.

In addition to its environmental benefits CSA cement can be utilised either alone or as an addition to PC to produce shrinkage-compensating, self-stressing, high-early-strength and rapidsetting cements (Beretka et al., 1996; Bernardo et al., 2006, 2007; Buzzi et al., 2010; Chen et al., 2012; Cohen and Richards, 1982; Gastaldi et al., 2011). To produce shrinkagecompensating and self-stressing CSA cements, the cement paste must expand. The right timing for expansion is crucial. Expansion without deleterious cracking is most easily achieved 
during early ages of hydration and strength gain; however, if expansion occurs after the paste has hardened and densified its microstructure sufficiently, then cracking is likely to occur. The use of CSA cement to produce expansive cements dates back to work by A. Klein in the 1960s (Klein et al., 1961). CSA-based cement's expansive nature quickly sparked a debate about the mechanism of expansion, with two competing schools of thought: crystal growth theory and swelling theory (Cohen, 1983). Swelling theory attributes expansion to the adsorption of water and swelling characteristics of 'ettringite gel,' whereas crystal growth theory attributes expansion to the growth of ettringite crystals on the expansive particles or from the solution resulting in a crystallisation pressure. The two theories may seem very different, but considering that the uptake of water is also a fundamental part of the crystallisation process of ettringite, the practical implication of both historically different schools of thought are rather similar.

Discussions and research on the thermodynamics of crystallisation in stone and cementitious materials have furthered the understanding of how the growth of crystals converts chemical potential into crystallisation pressure, which can exert mechanical force on the microstructure resulting in macroscopic strains (Flatt, 2002; Flatt and Scherer, 2008; Scherer, 1999, 2004; Steiger, 2005a, 2005b, 2006; Xie and Beaudoin, 1992). As Flatt, Scherer and Steiger have presented the thermodynamic calculations thoroughly, only the findings most relevant to the topic of expansion in CSA cements will be discussed briefly here. Their calculations show that crystallisation pressure increases with increasing supersaturation of the pore fluid with respect to the crystallising phase and size of the crystal growing in a confining pore separated by a 1-2 nm water layer.

Thermodynamic calculations initially were utilised to show how salts crystallising could generate stresses in pores of stone or concrete (Flatt, 2002; Scherer, 2004; Steiger, 2005a, 2005b), but were soon also utilised to explain the expansion caused by delayed ettringite formation (DEF) (Flatt and Scherer, 2008). Sant et al. (2011) utilised the concept of crystallisation pressure to explain how shrinkage-reducing admixtures elevate the supersaturation of portlandite in the pore solution at early ages, leading to a corresponding expansion. Bizzozero et al. (2014) investigated the effect of increasing calcium sulfate content on CSA and calcium aluminate cement pastes. Analysing the pore solutions of the pastes at $7 \mathrm{~d}$, they found that there was a threshold of calcium sulfate where the $\mathrm{Ca}^{2+}$ concentration increased rapidly, which results in higher saturation indices (SIs) for ettringite and, as a consequence of the higher SI, higher crystallisation pressures for a given pore size and the ability for crystals to exert sufficient pressure over a wider range of the porosity. Chaunsali and Mondal (2015a, 2015b, 2016) investigated PC-CSA blends. They analysed the pore solution of the blends at 1,3 and $7 \mathrm{~d}$ in all three studies and additionally at $21 \mathrm{~d}$ in their study where additional supplementary cementitious materials were included. They too found that early-age expansion was associated with supersaturation with respect to ettringite.

The chemical and physical factors affecting the amount and timing of CSA cement expansion are understood to include: (a) calcium sulfoaluminate and calcium aluminate content (principally ye'elimite content); (b) particle size distribution of the CSA cement; $(c)$ calcium sulfate content; $(d)$ calcium sulfate reactivity; (e) water availability, both in terms of the water/cement ratio $(w / c)$ and curing conditions; and $(f)$ lime and alkali content (Beretka et al., 1996; Chen et al., 2012; Cohen and Richards, 1982; Glasser and Zhang, 2001; Kurdowski and Thiel, 1981; Deng and Tang, 1994; Odler and Colan-Subauste, 1999; Wang et al., 1992). These factors affect the amount, timing and space available for hydration products to form. Considering these factors with regard to crystallisation pressure, it can be observed that increasing reactants that form ettringite should increase the supersaturation with regard to ettringite, as they dissolve and come into solution, and that varying their proportions will affect the microstructure and porosity in which the crystals will grow.

The aim of the present study is to build upon the growing body of evidence that crystallisation pressure is responsible for expansion in CSA cement-based systems by investigating the hydration of a variety of CSA cements with calcium sulfate to ye'elimite molar ratios $(M)$ ranging from $0 \cdot 1$ to 2 and monitoring their expansion from approximately $30 \mathrm{~min}$ to $182 \mathrm{~d}$. By monitoring the hydration over a much broader period of time compared to the earlier studies, the present study seeks to further understand CSA cement hydration and pore solution development and bring additional insights regarding how crystallisation pressure is affecting CSA cement expansion.

\section{Materials and methods}

Materials

A high ye'elimite CSA clinker was blended with gypsum to produce CSA cements with molar ratios of calcium sulfate/ye'elimite of $0 \cdot 1,1,1.5$ and 2 . Table 1 gives the CSA clinker and gypsum's oxide compositions, as determined by $\mathrm{X}$-ray fluorescence (XRF) and presents the density, Blaine fineness and phase quantification determined by quantitative $\mathrm{X}$-ray diffraction (XRD) for all cementitious components utilised.

\section{Methods}

Pastes

Cement pastes were prepared using the ratios in Table 2. For purposes of calculating $w / c$, cement was considered as CSA clinker plus gypsum. A retarder was not utilised in this study because all samples were able to be cast without one; also, not using a retarder avoids adding further ions to the pore solution, which could complicate analysis of the results, 
Table 1. CSA clinker and gypsum's chemical composition, density and fineness

\begin{tabular}{|c|c|c|c|c|c|}
\hline & CSA clinker & Gypsum & & CSA clinker & Gypsum \\
\hline Silicon dioxide $\left(\mathrm{SiO}_{2}\right)$ & $9 \cdot 52$ & $0 \cdot 32$ & $\mathrm{C}_{4} \mathrm{~A}_{3} \overline{\mathrm{S}}$ & $64 \cdot 4$ & - \\
\hline Aluminium oxide $\left(\mathrm{Al}_{2} \mathrm{O}_{3}\right)$ & $31 \cdot 51$ & 0.05 & $\mathrm{C}_{2} \mathrm{~S}$ & $7 \cdot 7$ & - \\
\hline Iron (III) oxide $\left(\mathrm{Fe}_{2} \mathrm{O}_{3}\right)$ & $1 \cdot 31$ & 0.04 & $\mathrm{C}_{9} \mathrm{~S}_{3} \overline{\mathrm{S}}_{3} \cdot \mathrm{CaF}_{2}$ & $6 \cdot 4$ & - \\
\hline Calcium oxide $(\mathrm{CaO})$ & $40 \cdot 14$ & $33 \cdot 87$ & $\mathrm{M}$ & $3 \cdot 1$ & - \\
\hline Magnesium oxide (MgO) & $4 \cdot 17$ & $0 \cdot 39$ & $\mathrm{C}_{3} \mathrm{MS}_{2}$ & $6 \cdot 9$ & - \\
\hline Sulfur trioxide $\left(\mathrm{SO}_{3}\right)$ & $10 \cdot 07$ & $44 \cdot 25$ & $\mathrm{C}_{7} \mathrm{MS}_{4}$ & $5 \cdot 6$ & - \\
\hline Sodium oxide $\left(\mathrm{Na}_{2} \mathrm{O}\right)$ & 0.49 & 0.06 & CT & $1 \cdot 7$ & - \\
\hline Potassium oxide $\left(\mathrm{K}_{2} \mathrm{O}\right)$ & 0.47 & 0.04 & $\mathrm{C}_{2} \mathrm{AS}$ & $2 \cdot 9$ & - \\
\hline Titanium dioxide $\left(\mathrm{TiO}_{2}\right)$ & 0.41 & 0.016 & $C \bar{C}$ & - & $1 \cdot 1$ \\
\hline Phosphorus pentoxide $\left(\mathrm{P}_{2} \mathrm{O}_{5}\right)$ & $0 \cdot 12$ & 0.006 & $C \bar{S}$ & $1 \cdot 3$ & $2 \cdot 4$ \\
\hline Manganese oxide $(\mathrm{MnO})$ & $0 \cdot 17$ & 0.003 & $\mathrm{C} \bar{S} \mathrm{H}_{0.5}$ & - & 0.8 \\
\hline Chromium (III) oxide $\left(\mathrm{Cr}_{2} \mathrm{O}_{3}\right)$ & 0.07 & 0.002 & $\mathrm{C} \overline{\mathrm{S}} \mathrm{H}_{2}$ & - & $95 \cdot 4$ \\
\hline Loss on ignition (LOI) & 0.61 & 21.02 & $\mathrm{~S}$ & - & 0.3 \\
\hline \multirow[t]{3}{*}{ Sum } & $99 \cdot 06$ & $99 \cdot 95$ & Sum & $100 \cdot 0$ & $100 \cdot 0$ \\
\hline & & & Blaine: $\mathrm{cm}^{2} / \mathrm{g}$ & 4750 & 4430 \\
\hline & & & Density: $\mathrm{g} / \mathrm{cm}^{3}$ & $2 \cdot 85$ & $2 \cdot 31$ \\
\hline
\end{tabular}

Table 2. Paste formulations for $1000 \mathrm{~cm}^{3}$

\begin{tabular}{|c|c|c|c|c|c|c|c|c|c|}
\hline Mix & & M0.1 & & M1 & & & M1.5 & & M2 \\
\hline$w / c^{a}$ & & $0 \cdot 8$ & & 0.8 & & & 0.8 & & 0.8 \\
\hline M & & $0 \cdot 1$ & & 1 & & & $1 \cdot 5$ & & 2 \\
\hline Material & Density: $\mathbf{g} / \mathrm{cm}^{3}$ & Mass: $\mathbf{g}$ & Vol.: $\mathrm{cm}^{3}$ & Mass: $\mathbf{g}$ & Vol:: $\mathrm{cm}^{3}$ & Mass: g & Vol.: $\mathrm{cm}^{3}$ & Mass: $\mathbf{g}$ & Vol.: $\mathrm{cm}^{3}$ \\
\hline CSA clinker & $2 \cdot 85$ & $868 \cdot 9$ & 304.9 & $734 \cdot 8$ & $257 \cdot 8$ & $676 \cdot 8$ & $237 \cdot 5$ & $627 \cdot 2$ & $220 \cdot 1$ \\
\hline Gypsum & $2 \cdot 31$ & 0 & 0 & $125 \cdot 2$ & $54 \cdot 2$ & $179 \cdot 3$ & $77 \cdot 6$ & $225 \cdot 6$ & $97 \cdot 7$ \\
\hline Water & 1 & $695 \cdot 1$ & $695 \cdot 1$ & 688.0 & 688.0 & 684.9 & 684.9 & $682 \cdot 3$ & $682 \cdot 3$ \\
\hline
\end{tabular}

If adjusted for the calcium sulfate's chemically bound water, the w/c equals $0.83,0.84$ and 0.85 for M1, M1.5 and M2, respectively

because chemical admixtures have been shown to affect chemical species' oversaturation levels in the pore solution and crystallisation pressure (Sant et al., 2011). Pastes were mixed for $2 \mathrm{~min}$ by an overhead mixer, revolving the paddle at a rate of $140 \mathrm{r} / \mathrm{min}$ with a planetary motion of approximately $62 \mathrm{r} / \mathrm{min}$. The pastes were then transferred to $500 \mathrm{ml}$ polyethylene bottles, taking care to remove as much air as possible while capping the bottles. The bottles were slowly rotated to avoid segregation until final setting, approximately $2 \mathrm{~h}$. The pastes were stored in the sealed bottles at $20^{\circ} \mathrm{C}$ and $95 \%$ relative humidity (RH) through $24 \mathrm{~h}$ of hydration, then demoulded, and the top and bottom of the moulded pastes were cut off to create cylinders $(100 \mathrm{~mm} \times 77 \mathrm{~mm}$ dia. $)$. All cylinders were then placed in sealed 11 plastic cylinders with $500 \mathrm{ml}$ of deionised water, which fully submersed the paste cylinders in water while trying to minimise the amount of water surrounding the pastes and interaction with the atmosphere.

\section{Dimensional stability}

For dimensional stability tests in water, stainless steel plugs were affixed to the ends of the paste cylinders using water and chemically resistant epoxy immediately after demoulding and before placing the cylinders in water to cure beyond $1 \mathrm{~d}$ of hydration. Length measurements were taken at 1.08 (reference measurement immediately after attaching stainless steel plugs), $1 \cdot 25,2,3,4,7,10,14,21,29,43,56,175$ and $182 \mathrm{~d}$ of hydration. The length measurements were taken on two cylinders for each mix and then the results were averaged. The error is estimated to be $\pm 0.05 \mathrm{~mm} / \mathrm{m}$, which was determined from the maximum length change difference between any two cylinders for all length measurements.

To study the dimensional stability of the pastes immediately after setting, autogenous strain tests were performed according ASTM C 1698 (ASTM, 2009; Wyrzykowski et al., 2016). Pastes were placed in corrugated tubes utilising vibration. The tubes were then rotated for $30 \mathrm{~min}$ during the period when trial samples experienced bleeding, but had not yet experienced initial set. The plastic pastes were then placed into a temperature-controlled silicone oil bath at $20 \pm 0 \cdot 1^{\circ} \mathrm{C}$. The length changes were recorded after initial shrinkage terminated (probably in the plastic state) and final setting was achieved, approximately $120-160 \mathrm{~min}$ of hydration. The length change was measured for $7 \mathrm{~d}$. 


\section{Tensile strength}

Paste cylinders were prepared as previously described and demoulded after $24 \mathrm{~h}$ of curing. The top and bottom of the specimens were cut off and polished afterwards. Steel discs were glued to the upper and lower ends of the cylinders by means of a rapid-hardening epoxy resin. The steel discs were attached to a tensile loading machine and the tensile strength was measured using a loading rate of $0.05 \mathrm{MPa} / \mathrm{s}$.

\section{X-ray diffraction and thermogravimetric analysis}

Hydration was stopped on cylinders at $0 \cdot 5,1,7,14,28,56$ and $182 \mathrm{~d}$ of hydration by slicing a $5 \mathrm{~mm}$ thick section from the centre of a cylinder, then crushing in isopropanol in an agate mortar for $5 \mathrm{~min}$, followed by soaking in isopropanol for an additional $10 \mathrm{~min}$. The isopropanol was then filtered off, and the pastes were soaked in di-ethyl ether for $5 \mathrm{~min}$. The ether was then filtered off, and the pastes were dried for $20 \mathrm{~min}$ at $40^{\circ} \mathrm{C}$. The pastes were then studied using thermogravimetric analysis (TGA) and XRD. TGA was conducted on a Mettler Toledo TGA/SDTA 851e from 30 to $980^{\circ} \mathrm{C}$ using $50 \pm 2 \mathrm{mg}$, a $20^{\circ} \mathrm{C} / \mathrm{min}$ heating rate and nitrogen as the protective gas. The relative error is estimated at $5 \%$, which produces an absolute error of $\pm 2 \%$ at $980^{\circ} \mathrm{C}$.

The XRD was conducted using a PANalytical X'Pert Pro diffractometer equipped with an X'Celerator detector. The incident beam was $\mathrm{Co}_{\alpha}$ radiation $(0 \cdot 1789 \mathrm{~nm})$ with a $1 / 2^{\circ}$ and $1^{\circ}$ divergence and anti-scatter slit, respectively. A $2 \theta$ range of $5-65^{\circ}$ was scanned continuously over $2 \mathrm{~h}$. Samples were prepared by back loading. An internal standard of $20 \%$ calcium fluoride $\left(\mathrm{CaF}_{2}\right)$ was utilised. The Rietveld analysis was performed using PANalytical Highscore Plus 3.0.5 software. The background was fit manually using a cubic spline with base points at the same $2 \theta$ positions for all patterns. Scale factors, lattice parameters, pattern shift and specimen displacement were refined. Multiple polymorphs for belite and ye'elimite were considered (Le Saout et al., 2011). Ye'elimite was quantified using both an orthorhombic and cubic structure, which improved the pattern fit but did not significantly change the quantification (Alvarez-Pinazo et al., 2012; Calos et al., 1995; Hargis et al., 2014), and the beta polymorph of $\mathrm{C}_{2} \mathrm{~S}$ was found to provide the best fit.

\section{Pore solution analysis}

Pore solutions were expressed using the steel die method (Barneyback and Diamond, 1981) and immediately filtered using $0 \cdot 45 \mu \mathrm{m}$ nylon filters. For ion chromatography analysis, one part of the solution was immediately diluted to $1: 10$, $1: 100$ and $1: 1000$ with deionised water $(18 \cdot 2 \mathrm{M} \Omega)$. The total concentrations of the sodium, potassium, calcium, chloride, sulfate, aluminate and silicate ions were determined using ion chromatography (Dionex ICS 3000 with columns: IonPac CS12A, AS22 and CS5A). The other part was used for $\mathrm{pH}$ measurements. The hydroxide concentrations were determined with a combined $\mathrm{pH}$ electrode on the filtered and undiluted solutions. The $\mathrm{pH}$ electrode was calibrated against potassium hydroxide solutions of known concentrations.

Utilising the ion concentrations from the expressed pore solutions, saturation indices for the hydration products were calculated using the Gibbs free energy minimisation software, GEMS-PSI (Kulik et al., 2013; Wagner et al., 2012). Any pH adjustments necessary to match the experimental data were made by reducing sodium hydroxide $(\mathrm{NaOH})$ or hydrochloric acid $(\mathrm{HCl})$ as necessary. Any adjustments made were kept to a minimum because the ion activity products (IAPs) of many hydration products are sensitive to changes in the concentration of hydroxide ions $\left(\mathrm{OH}^{-}\right)$. The IAP of ettringite is equal to $\left\{\mathrm{Ca}^{2+}\right\}^{6}\left\{\mathrm{Al}(\mathrm{OH})_{4}{ }^{-}\right\}^{2}\left\{\mathrm{OH}^{-}\right\}^{4}\left\{\mathrm{SO}_{4}{ }^{2-}\right\}\left\{\mathrm{H}_{2} \mathrm{O}\right\}^{26}$, so any change to the hydroxide ion concentration gets raised to the fourth power and can have large effects on the calculated SI.

'GEMS' is a broad-purpose geochemical modelling code which computes the equilibrium phase assemblage and speciation in a complex chemical system from its total bulk elemental composition. The thermodynamic data for aqueous species and solids were taken from the PSI-GEMS thermodynamic database with the PSI-Nagra database (Hummel et al., 2002). For cement minerals, the cement-specific CEMData14 database (Lothenbach et al., 2008, 2012; Matschei et al., 2007) was used. A summary of the thermodynamic database is also available at Empa (2018), where the thermodynamic database in the GEMS format can be freely downloaded. The activity coefficients of the aqueous species $\gamma_{i}$ were computed with the built-in extended Debye-Hückel equation with common ion-size parameter $a_{i}$ of $0.367 \mathrm{~nm}$ for potassium hydroxide solutions and common third parameter $b_{y}$ according to Equation 1

1. $\log \gamma_{i}=\frac{-A_{y} z_{i}^{2} \sqrt{I}}{1+B_{y} a_{i} \sqrt{I}}+b_{y} I$

where $\mathrm{z}_{i}$ denotes the charge of species $i ; I$ is the effective molal ionic strength; $b_{y}$ is a semi-empirical parameter $(\sim 0.123$ for potassium hydroxide electrolyte at $25^{\circ} \mathrm{C}$ ); and $A_{y}$ and $B_{y}$ are $P$, $T$-dependent coefficients. This activity correction is applicable up to approximately $1 \mathrm{M}$ ionic strength (Merkel and Planer-Friederich, 2008).

Depending on the equilibration time and temperature, aluminium hydroxide $\left(\mathrm{AH}_{3}\right)$ forms with different degrees of crystallinity, which results in different solubility products (Lothenbach et al., 2012). During the first hours of hydration, an amorphous $\mathrm{AH}_{3}$ with a $\log K_{\mathrm{s} 0}\left(\mathrm{Al}(\mathrm{OH})_{3}^{0}+\mathrm{OH}^{-} \leftrightarrow \mathrm{Al}\right.$ $(\mathrm{OH})_{4}^{-}$) of $\sim 0$ forms, which only transforms during months to years to microcrystalline $\mathrm{AH}_{3}$ with a solubility product of -0.67 at ambient temperature. Crystalline gibbsite $\left(\log K_{\mathrm{s} 0}=-1 \cdot 12\right)$ is even more stable, but forms only at higher temperatures or very long equilibration times. Thus $\mathrm{AH}_{3}$ solubility was varied as a function of time based on the data 
reported in Lothenbach et al. (2012), see Figure 1. The data from Capmas and Ménétrier-Sorrentino (1989) (3 to $9 \mathrm{~min}$ ) and Pokrovskii and Helgeson (1995) (gibbsite) were omitted from the equation fit because their exact times could not be determined but are shown for reference. The water content of $\mathrm{AH}_{3}$ and its resulting molar volume were not varied in this study because of uncertainty about the amount of bound water and the timing of the change in bound water over time (Cuesta et al., 2017a; Jansen et al., 2017).

In addition to calculating the saturation indices, thermodynamic modelling was utilised to calculate the phase assemblages at $0 \cdot 5,1,7,14,28,56$ and $182 \mathrm{~d}$ of hydration. The consumption of anhydrous phases as determined from the Rietveld analysis of the XRD data was fit using a four-parameter logistic non-linear regression model and was then input into GEMS to provide the kinetic restraint on the anhydrous phase consumption (Chitvoranund et al., 2017). GEMS was then used to calculate the hydration phase assemblage at $20^{\circ} \mathrm{C}$ and atmospheric pressure. The experimental temperature affects ion solubility and reaction kinetics, so conducting experiments and modelling at different temperatures can cause different results.

The mercury intrusion porosimetry (MIP) tests were performed on Pascal 140/440 (Thermo Fisher Scientific Inc.) instruments. The MIP mortar samples were dried in the same manner as the XRD samples. Approximately $1 \mathrm{~g}$ of mortar was first intruded to a mercury pressure, $P_{\mathrm{Hg}}$, of $395 \mathrm{kPa}$ on the Pascal 140 , then the sample was moved to the Pascal 440 and intruded to $200 \mathrm{MPa}$. A cylindrical pore model and the Washburn equation (Equation 2) using a contact angle, $\theta_{\mathrm{Hg}}=140^{\circ}$, and a surface tension, $\gamma_{\mathrm{Hg}}=0.48 \mathrm{~N} / \mathrm{m}$, were assumed for intrusion to calculate the pore radius, $r_{\mathrm{p}}$ (Kaufmann, 2010).

2. $r_{\mathrm{p}}=\frac{2 \gamma_{\mathrm{Hg}} \cos \theta_{\mathrm{Hg}}}{P_{\mathrm{Hg}}}$

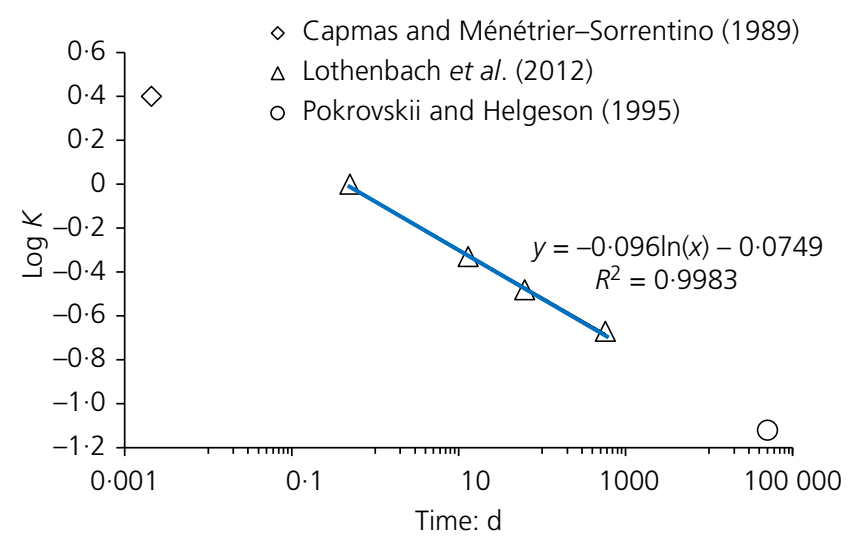

Figure 1. Solubility of $\mathrm{AH}_{3}$ as a function of time

\section{Results}

\section{Physical stability}

\section{Long-term mass change}

Figure 2 presents the mass gain for the CSA cement paste cylinders whose length changes are presented later in Figure 4. Similar to the length change results, the CSA cement pastes with added gypsum gained mass at a faster rate with increasing calcium sulfate content, and their rates of mass gain declined with time. As is the case for its length change, M0 1 gained less mass initially compared to the CSA cement pastes with added calcium sulfate, but sustained additional mass gain through $182 \mathrm{~d}$ of hydration. Mass gain during water curing increased with increasing gypsum content due to the increased production of hydration products and water absorbed in cracks and microcracks, which will be discussed subsequently.

\section{Early-age length change}

The length changes of the cement pastes as measured by ASTM C 1698 are presented in Figure 3. After setting, all pastes initially expand; however, M0 1 begins to contract after $6 \mathrm{~h}$; whereas all pastes with added gypsum continue to expand further. M1 expands to a maximum strain of $2 \cdot 3 \mathrm{~mm} / \mathrm{m}$ at $16 \mathrm{~h}$ of hydration, after which it slowly contracts. M1.5 expands to a strain of $2.7 \mathrm{~mm} / \mathrm{m}$ at $14 \mathrm{~h}$ of hydration, after which it contracts to $2.3 \mathrm{~mm} / \mathrm{m}$ at $22 \mathrm{~h}$ before continuing to expand to a maximum strain of $2.7 \mathrm{~mm} / \mathrm{m}$ at $7 \mathrm{~d}$. M2 expands to a maximum strain of $3.6 \mathrm{~mm} / \mathrm{m}$ at $15 \mathrm{~h}$ of hydration, after which it contracts to $2.8 \mathrm{~mm} / \mathrm{m}$ at $36 \mathrm{~h}$ before continuing to expand to $3.5 \mathrm{~mm} / \mathrm{m}$ at $7 \mathrm{~d}$. The periods of contraction that all the pastes experience are likely to be attributable to chemical shrinkage, since all pastes have sufficient water for hydration and should not be self-desiccating leading to autogenous shrinkage. For the pastes that continue to expand through $7 \mathrm{~d}$ (M1.5 and M2), the period of contraction would

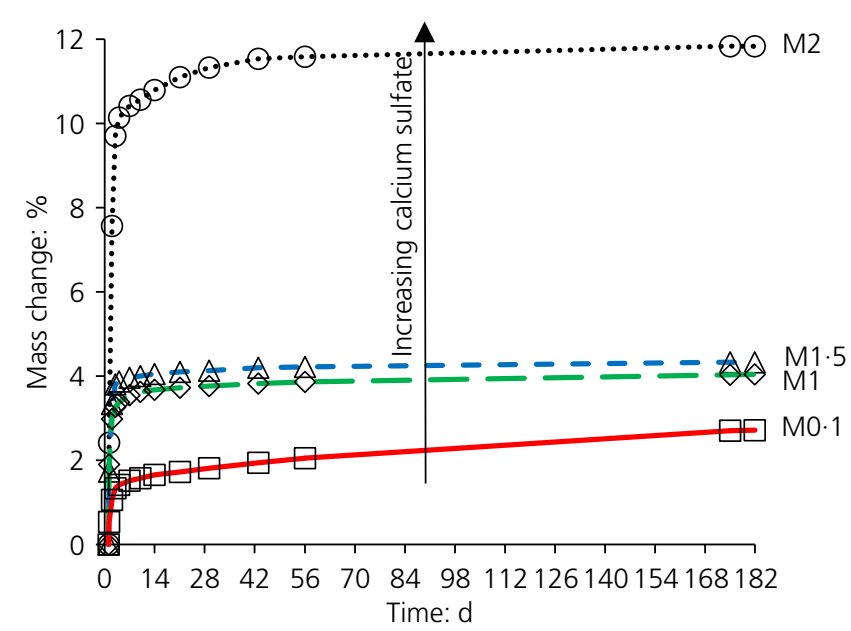

Figure 2. Mass change of CSA cement pastes through $182 \mathrm{~d}$ of hydration 


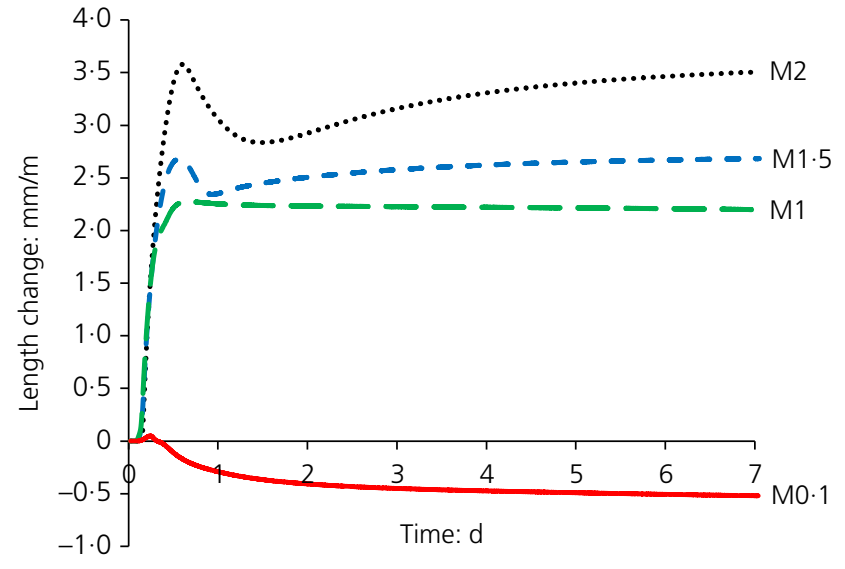

Figure 3. Early-age length change of CSA cement pastes

represent a stage of hydration where the chemical shrinkage exceeds the strain induced from crystallisation, and the periods of expansion represent the stages of hydration where the strains induced by crystallisation exceed the chemical shrinkage. It is important to note that expansion begins at $2 \cdot 5,2 \cdot 0$, $2 \cdot 2$ and $2 \cdot 7 \mathrm{~h}$ for $\mathrm{M} 0 \cdot 1, \mathrm{M} 1, \mathrm{M} 1 \cdot 5$ and $\mathrm{M} 2$, respectively. Many dimensional stability tests begin at $1 \mathrm{~d}$ of hydration. As a consequence, those studies could be missing $2-3 \mathrm{~mm} / \mathrm{m}$ of expansion during the first day of hydration, which is often as much as the total expansion reported over months of hydration.

\section{Long-term length change}

Figure 4 presents the expansion of paste cylinders demoulded at $1 \mathrm{~d}$ of hydration and stored in water thereafter. M2 expanded rapidly and cracked during the initial day of water storage; it continued to show movement through $21 \mathrm{~d}$ of hydration. For the pastes with added calcium sulfate, the initial rates of expansion increased with increasing calcium sulfate content. Likewise, all pastes with added calcium sulfate had decreasing rates of expansion with time. In contrast, M0.1 expanded more slowly initially, but sustained a greater rate of expansion through the $182 \mathrm{~d}$ of testing.

\section{Hydration}

Equations I-IV give the CSA hydration reactions for ye'elimite and belite $\left(\mathrm{C}_{2} \mathrm{~S}\right)$ relevant to this study. Equations I and II give the hydration reactions for ye'elimite without and with added calcium sulfate to form $\mathrm{AH}_{3}$ and monosulfate or ettringite, respectively. Equation III gives the formation of strätlingite from belite and $\mathrm{AH}_{3}$. Equation IV gives the metastable formation of ettringite, $\mathrm{CAH}_{10}$ and $\mathrm{AH}_{3}$ from ye'elimite.

I. $\mathrm{C}_{4} \mathrm{~A}_{3} \overline{\mathrm{S}}+18 \mathrm{H} \rightarrow \mathrm{C}_{4} \mathrm{~A} \overline{\mathrm{S}} \mathrm{H}_{12}+2 \mathrm{AH}_{3}$

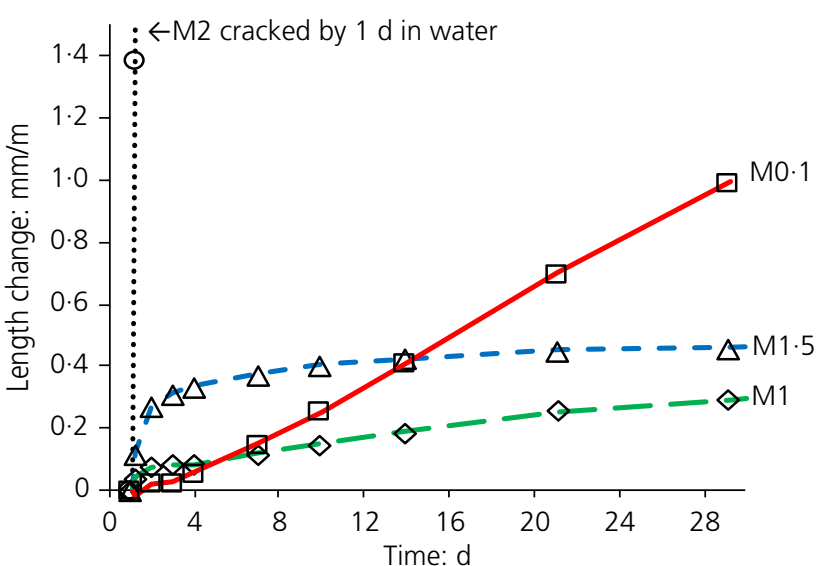

(a)

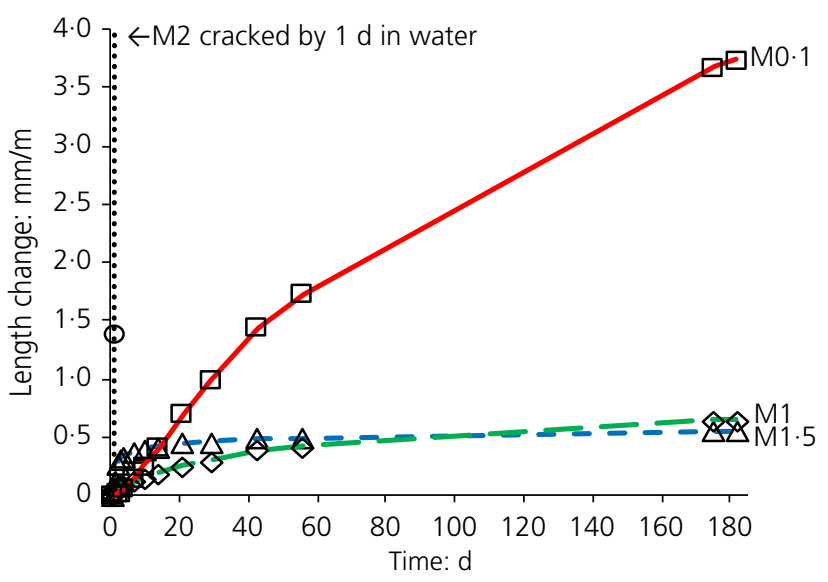

(b)

Figure 4. (a) Zoomed-in section of expansion through $29 \mathrm{~d}$ of hydration; (b) expansion of CSA cement pastes through $182 \mathrm{~d}$ of hydration

II. $\mathrm{C}_{4} \mathrm{~A}_{3} \overline{\mathrm{S}}+2 \mathrm{C} \overline{\mathrm{S}} \mathrm{H}_{2}+34 \mathrm{H} \rightarrow \mathrm{C}_{6} \mathrm{~A}_{3} \mathrm{H}_{32}+2 \mathrm{AH}_{3}$

III. $\mathrm{C}_{2} \mathrm{~S}+\mathrm{AH}_{3}+5 \mathrm{H} \rightarrow \mathrm{C}_{2} \mathrm{ASH}_{8}$

IV. $\quad 6 \mathrm{C}_{4} \mathrm{~A}_{3} \overline{\mathrm{S}}+133 \mathrm{H} \rightarrow 2 \mathrm{C}_{6} \mathrm{AS}_{3} \mathrm{H}_{32}+3 \mathrm{C}_{4} \mathrm{AH}_{10}+13 \mathrm{AH}_{3}$

Figure 5 presents the XRD patterns for the CSA cement pastes from $0 \cdot 5$ to $182 \mathrm{~d}$ of hydration. Some trends from the qualitative XRD can be observed. All CSA cement pastes' XRD patterns included the appearance of diffuse peaks at the position of gibbsite's main peaks, indicating the presence of poorly crystalline $\mathrm{AH}_{3}$ (outside the range shown). Second, ettringite content increased with increasing calcium sulfate content, as expected. Third, $\mathrm{CAH}_{10}$ formed as a metastable 


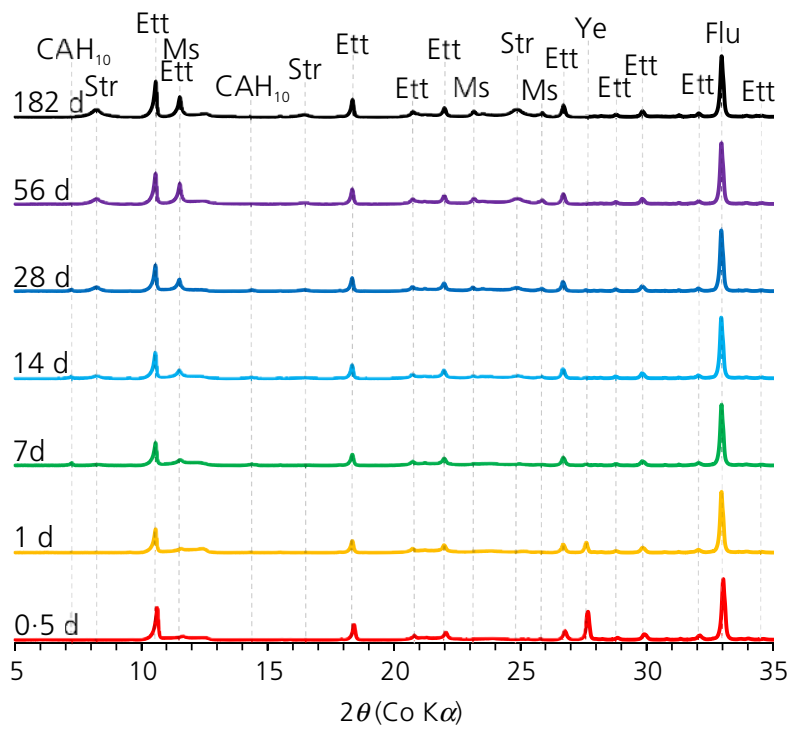

(a)

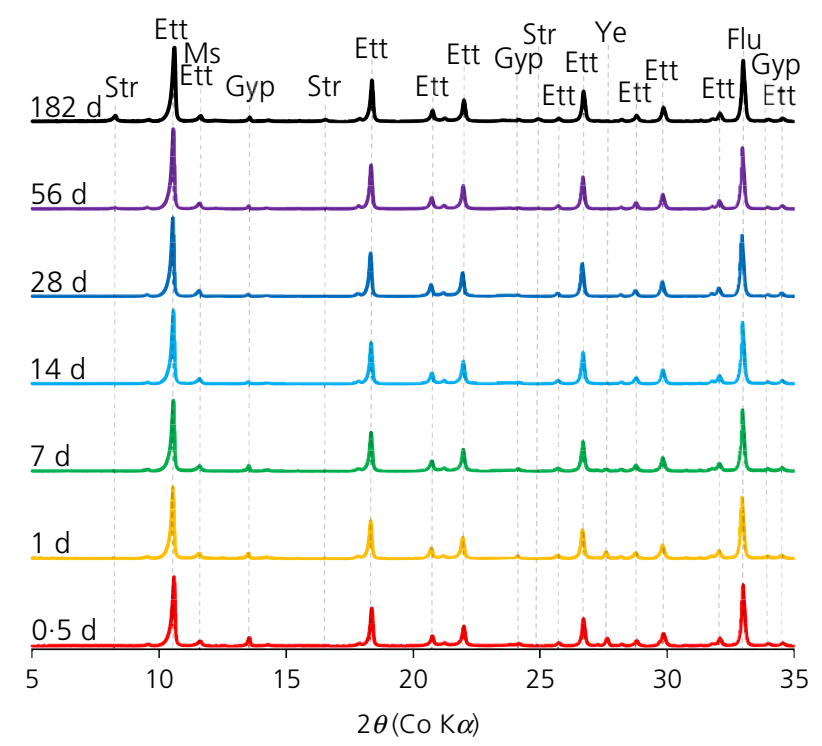

(c)

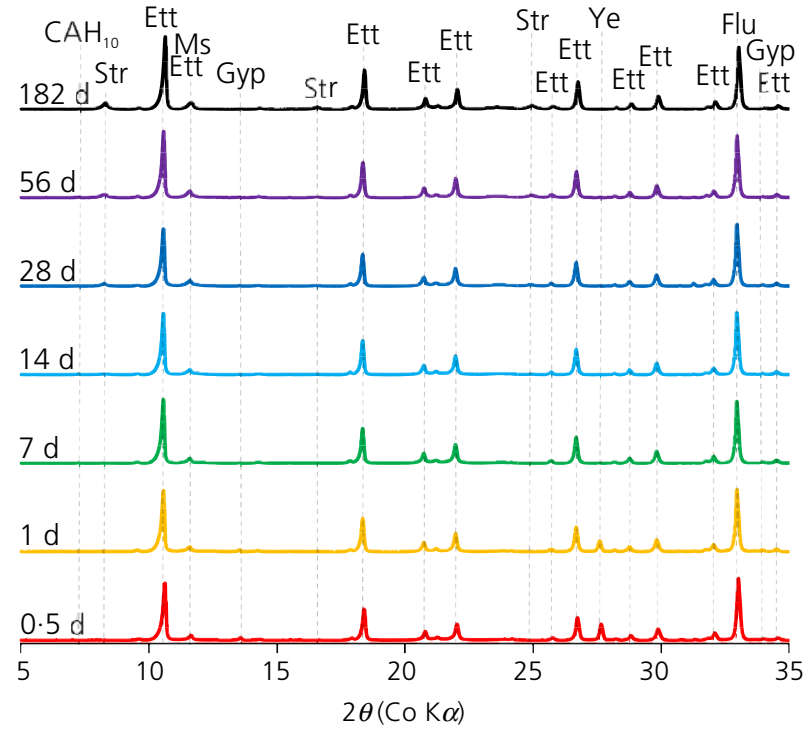

(b)

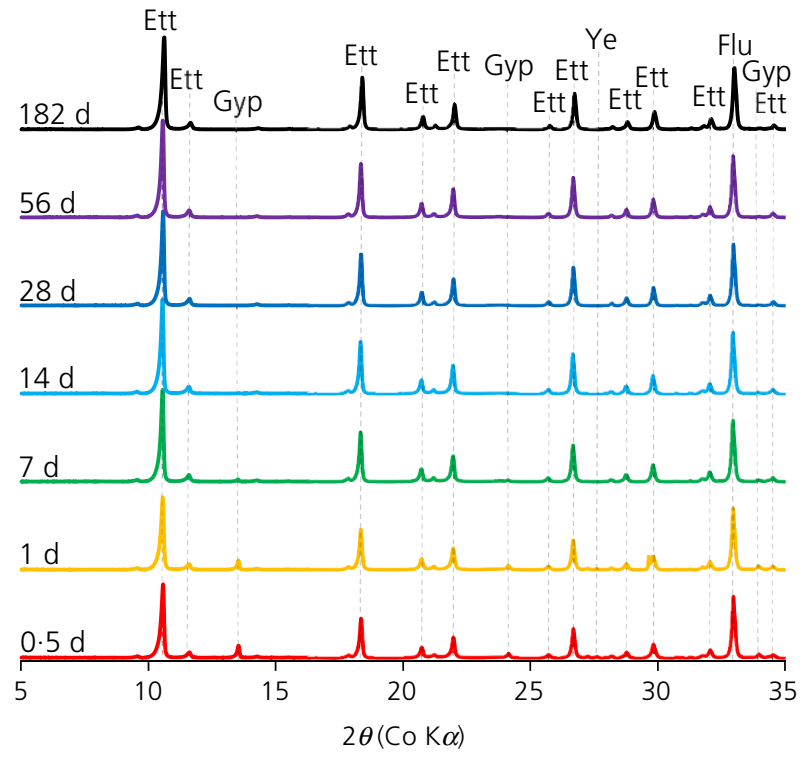

(d)

Figure 5. XRD patterns for: (a) M0.1; (b) M1; (c) M1.5; (d) M2 (Ett, ettringite; Ms, monosulfate; Str, strätlingite; Gyp, gypsum; Ye, ye'elimite; Flu, fluorite)

hydration product in the systems with the least calcium sulfate, M0.1 and M1. Fourth, the amount of strätlingite formed increased with decreasing calcium sulfate content, which is consistent with prior research (Jeong et al., 2018). M2 produced, in addition to $\mathrm{AH}_{3}$, only ettringite as a crystalline hydration product, but very little or no strätlingite, in contrast to the systems with less calcium sulfate.

Figure 6 presents the results from the Rietveld refinements performed on the XRD patterns in Figure 5. The quantity of ettringite produced increased with increasing gypsum content.
The majority of the ettringite produced formed in the first $12 \mathrm{~h}$ of hydration. $\mathrm{M} 0 \cdot 1$ and $\mathrm{M} 1$ continued to produce additional ettringite through $182 \mathrm{~d}$, and M1.5 and M2 have formed their maximum amount of ettringite by $56 \mathrm{~d}$. M0.1 formed the most crystalline monosulfate, and M1 formed the second most, as expected; however, M1.5 did not form a significant quantity of crystalline monosulfate through $182 \mathrm{~d}$. Monosulfate can form as part of AFm solid solutions; the presence of different anions lowers the crystallinity and thus limits the ability to quantify it by way of XRD, but the trends observed are as expected. 


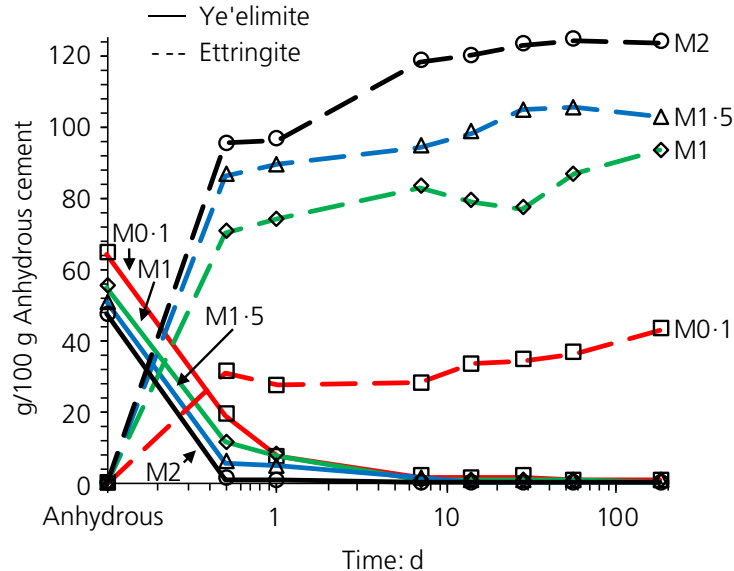

(a)

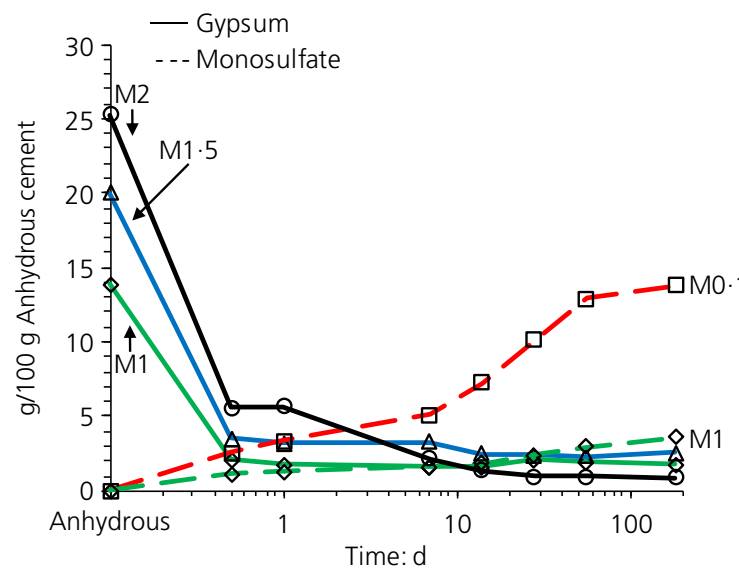

(c)

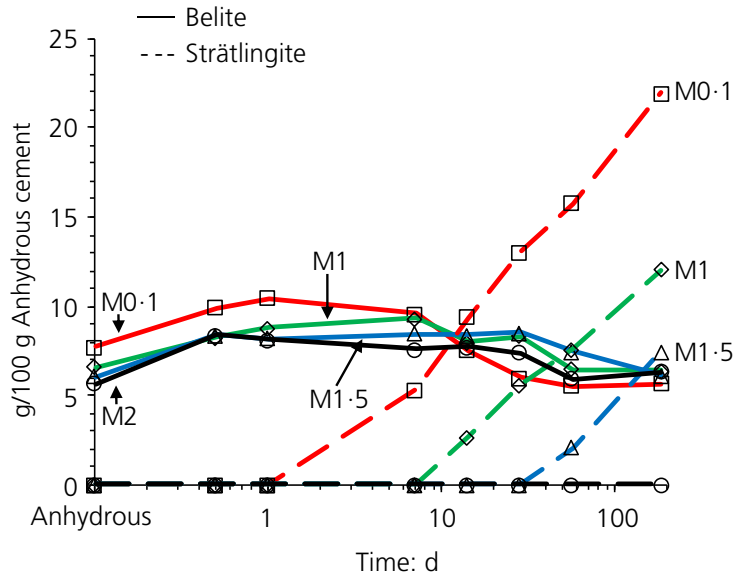

(b)

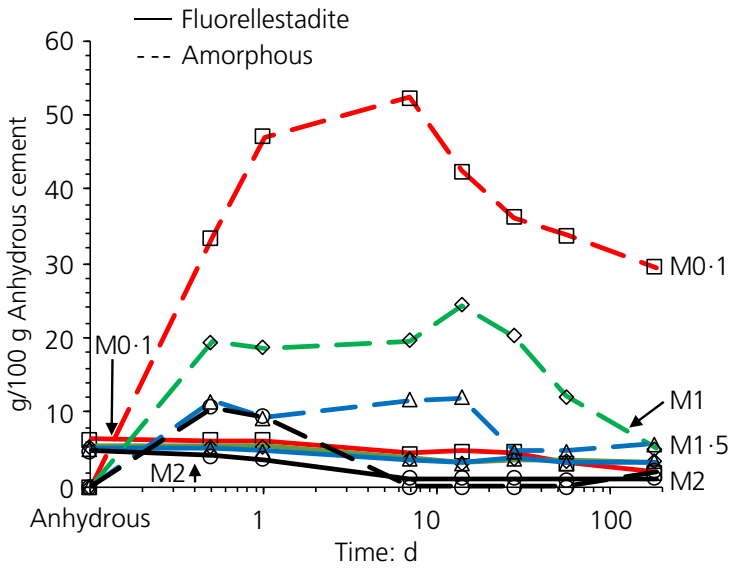

(d)

Figure 6. Quantification of XRD patterns by way of Rietveld refinement. Note: ordinate scale changes between plots

Increasing gypsum content accelerated the reaction of ye'elimite, which is consistent with prior studies (Winnefeld and Barlag, 2010). By $7 \mathrm{~d}$ of hydration, M0 1 and M2 had $2 \cdot 1$ and $0.3 \mathrm{~g}$ ye'elimite remaining, respectively. All systems have depleted the majority of their ye'elimite by $7 \mathrm{~d}$ of hydration, so additional ettringite or monosulfate production past that age is most likely in part due to crystallisation from amorphous hydration products, which peaked in quantity between 7 and $14 \mathrm{~d}$ and declined thereafter. In other words, amorphous hydration products which formed during the very rapid hydration of ye'elimite, when the kinetics of ye'elimite dissolution may have exceeded the kinetics of ettringite and monosulfate formation, later dissolved and recrystallised as more ordered and thermodynamically stable phases with lower solubility products than their amorphous precursors.

Increasing gypsum decreased the amount of strätlingite produced and delayed its starting point of formation. The cause of the change is three-fold. First, in the presence of sufficient gypsum, ettringite formation is thermodynamically favoured, which suppresses the formation of AFm phases such as monosulfate or strätlingite (Winnefeld and Lothenbach, 2016). Second, increasing gypsum content accelerates CSA cement hydration, which causes the paste microstructure to densify more extensively, which inhibits ion mobility and belite dissolution. Third, increasing gypsum reduces the amount of belite in the CSA cement by diluting the clinker content. The slight increase in the belite quantified between the anhydrous and the $12 \mathrm{~h}$ patterns is most likely attributed to peak overlap between belite and hydration products, resulting in a belite quantification that is overestimated by approximately $2 \mathrm{~g} / 100 \mathrm{~g}$ anhydrous cement in all hydrated systems. Fluorellestadite $\left(\mathrm{Ca}_{10}\left(\mathrm{SiO}_{4}\right)_{3}\left(\mathrm{SO}_{4}\right)_{3} \mathrm{~F}_{2}\right)$ slowly dissolves with time, providing ionic species that can be bound by AFm and AFt phases. Of specific note, the release of sulfate ions will promote the formation of ettringite, which has been shown in prior studies to contribute to expansion.

Figure 7 presents the thermodynamic modelling of CSA cement hydration utilising the quantitative XRD (QXRD) 


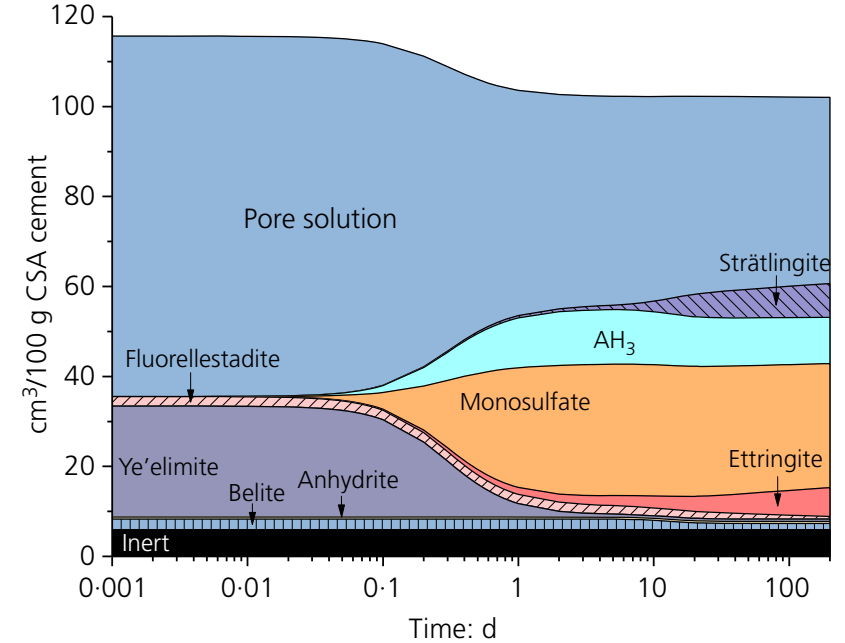

(a)

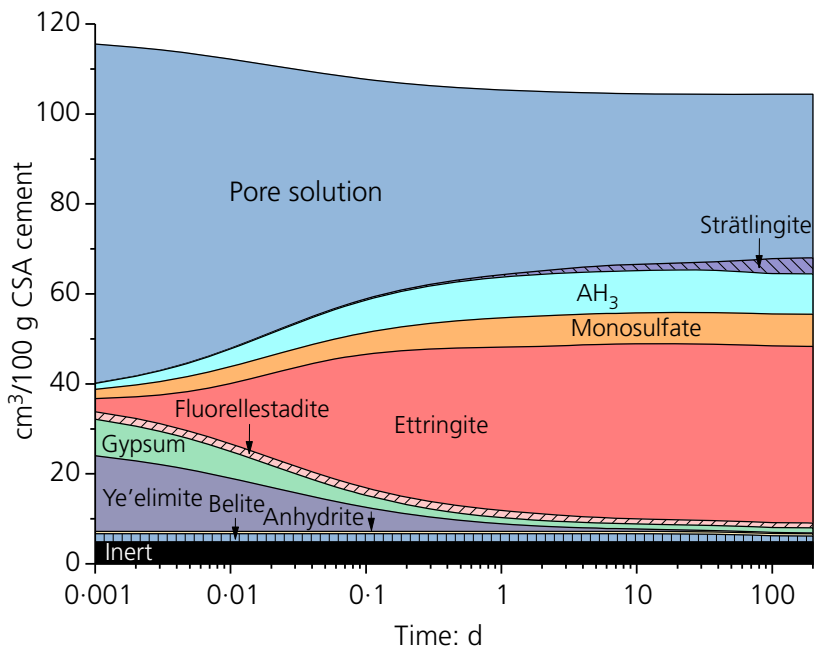

(c)

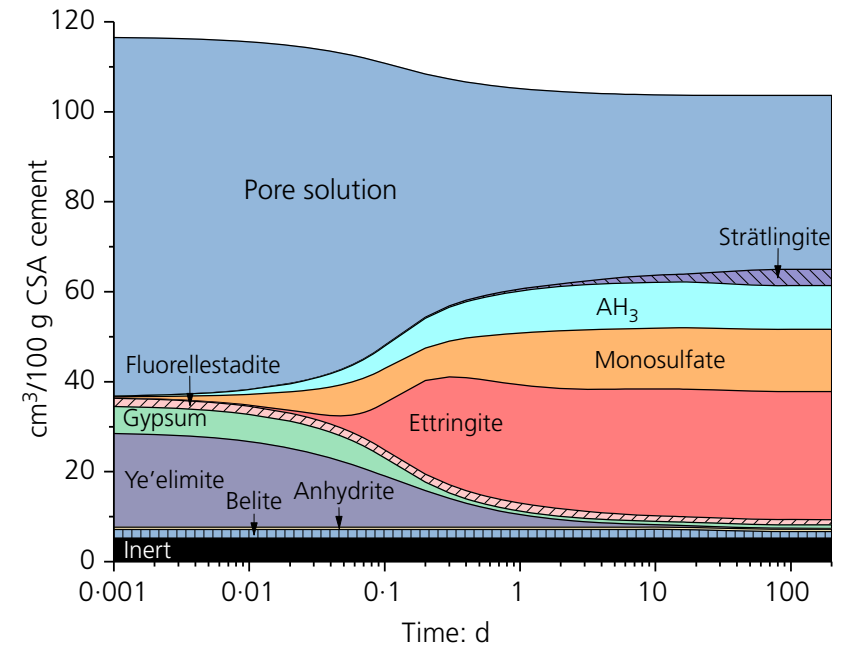

(b)

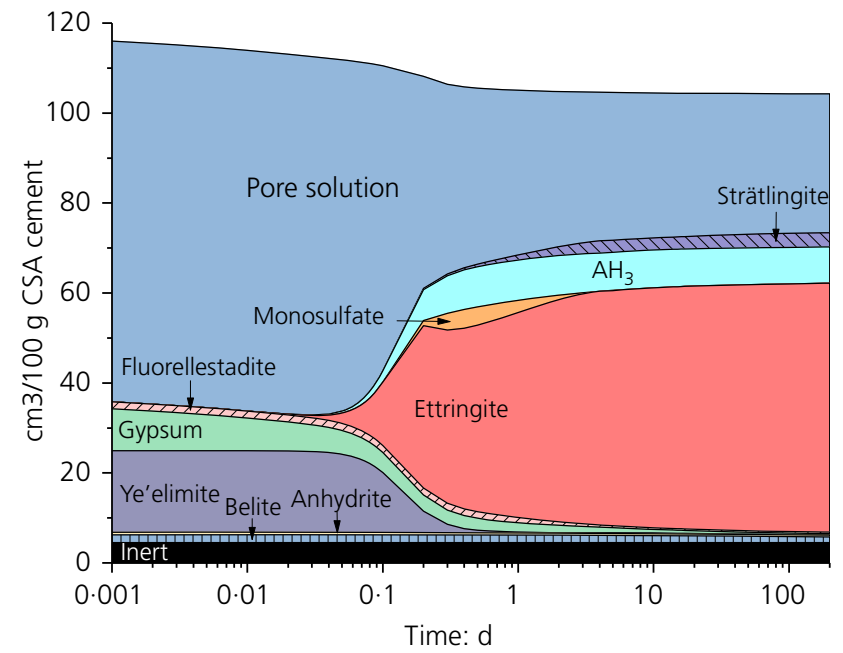

(d)

Figure 7. Thermodynamic modelling of CSA cement hydration over time: (a) M0.1; (b) M1; (c) M1.5; (d) M2

results presented in Figure 6 as the kinetic input. M0.1 is calculated to produce the most strätlingite, which is consistent with the XRD results. $\mathrm{CAH}_{10}$ is not predicted to form, as it is thermodynamically not stable (Winnefeld and Lothenbach, 2016). M0.1 is also calculated to produce an increasing amount of ettringite with time due to the small amount of anhydrite in the clinker, but more importantly due to the dissolution of fluorellestadite releasing sulfate ions. With increasing added gypsum, more ettringite is produced and less monosulfate is produced. In the M2 system, there is a transient formation of monosulfate around $1 \mathrm{~d}$ of hydration due to the ye'elimite dissolution out-pacing the calcium sulfate supply.

\section{Pore solution analysis}

The $\mathrm{pH}$ and ion concentrations from the pore solutions expressed are given in Table 3. At early ages calcium and sulfate concentrations increased with increasing gypsum content. Contrarily, aluminate and silicate ions decreased with increasing gypsum content due to the increased $\mathrm{Ca}^{2+}$ concentration. The higher sulfate concentrations in the presence of ettringite result in lower hydroxide concentrations and thus $\mathrm{pH}$ values than in the samples with lower sulfate concentration in the presence of both ettringite and monosulfate, so $\mathrm{M} 2$ had a lower $\mathrm{pH}$ compared to the other pastes. Additionally, M2 at $0.5 \mathrm{~d}$ was replicated to confirm the relatively low $\mathrm{pH}$ of 10 .

The SI of a phase is given as the log of the ion activity product (IAP) divided by the solubility product $\left(K_{\mathrm{sp}}\right)$ in Equation 3 . The SIs for the main phases of interest are given in Table 4. SIs which are positive indicate that the pore solution is oversaturated with regard to that species, indicating a driving force to precipitate that species, and SIs that are negative indicate the solution is undersaturated with regard to that species, 
Table 3. $\mathrm{pH}$ and ion concentrations in pore solutions

\begin{tabular}{|c|c|c|c|c|c|c|c|c|c|c|}
\hline & $\begin{array}{l}\text { Time: } \\
\text { d }\end{array}$ & $\mathrm{pH}$ & $\begin{array}{c}\text { Sodium: } \\
\mathrm{mmol} / \mathrm{l}\end{array}$ & $\begin{array}{c}\text { Potassium: } \\
\mathrm{mmol} / \mathrm{l}\end{array}$ & $\begin{array}{l}\text { Calcium: } \\
\mathrm{mmol} / \mathrm{l}\end{array}$ & $\begin{array}{c}\text { Chloride: } \\
\mathrm{mmol} / \mathrm{l}\end{array}$ & $\begin{array}{l}\text { Sulfate: } \\
\mathrm{mmol} / \mathrm{l}\end{array}$ & $\begin{array}{l}\text { Silicate: } \\
\mathrm{mmol} / \mathrm{I}\end{array}$ & $\begin{array}{c}\text { Aluminate: } \\
\mathrm{mmol} / \mathrm{l}\end{array}$ & $\begin{array}{c}\text { Hydroxide: } \\
\mathrm{mmol} / \mathrm{l}\end{array}$ \\
\hline \multirow[t]{7}{*}{ M0.1 } & 0.5 & $12 \cdot 7$ & 339.7 & $145 \cdot 3$ & $0 \cdot 11$ & $67 \cdot 3$ & 14.9 & $0 \cdot 12$ & $239 \cdot 4$ & $55 \cdot 0$ \\
\hline & 1 & $12 \cdot 7$ & 373.9 & $166 \cdot 7$ & $0 \cdot 11$ & 84.9 & $26 \cdot 5$ & 0.16 & $316 \cdot 0$ & 56.0 \\
\hline & 7 & $12 \cdot 8$ & 173.6 & $65 \cdot 4$ & $0 \cdot 10$ & $43 \cdot 7$ & $22 \cdot 1$ & 0.12 & $49 \cdot 4$ & $57 \cdot 2$ \\
\hline & 14 & $12 \cdot 8$ & 139.1 & $46 \cdot 0$ & 0.09 & $35 \cdot 2$ & $14 \cdot 1$ & $0 \cdot 10$ & $25 \cdot 2$ & $57 \cdot 2$ \\
\hline & 28 & $12 \cdot 8$ & $136 \cdot 4$ & $41 \cdot 8$ & 0.03 & 31.0 & 8.3 & 0.03 & $21 \cdot 2$ & $59 \cdot 3$ \\
\hline & 56 & $12 \cdot 7$ & $102 \cdot 9$ & 31.5 & 0.06 & $25 \cdot 7$ & 8.0 & 0.02 & $10 \cdot 3$ & $46 \cdot 8$ \\
\hline & 182 & $12 \cdot 7$ & 84.9 & $25 \cdot 6$ & $0 \cdot 16$ & $15 \cdot 7$ & 1.8 & 0.04 & $10 \cdot 1$ & 49.0 \\
\hline \multirow[t]{7}{*}{ M1 } & 0.5 & $12 \cdot 7$ & 332.6 & $136 \cdot 2$ & 0.07 & $85 \cdot 3$ & 48.9 & 0.25 & $213 \cdot 6$ & $44 \cdot 7$ \\
\hline & 1 & $12 \cdot 7$ & $337 \cdot 2$ & $149 \cdot 1$ & 0.07 & 92.5 & $35 \cdot 8$ & $0 \cdot 19$ & $249 \cdot 9$ & 48.8 \\
\hline & 7 & $12 \cdot 7$ & 172.7 & 62.5 & $0 \cdot 10$ & 43.8 & $18 \cdot 3$ & 0.12 & 72.9 & 51.4 \\
\hline & 14 & $12 \cdot 7$ & $130 \cdot 5$ & $46 \cdot 5$ & 0.09 & $31 \cdot 3$ & 13.0 & $0 \cdot 10$ & $46 \cdot 4$ & 47.9 \\
\hline & 28 & $12 \cdot 7$ & $100 \cdot 9$ & $35 \cdot 6$ & 0.04 & $19 \cdot 5$ & 5.9 & 0.06 & $42 \cdot 9$ & $45 \cdot 2$ \\
\hline & 56 & $12 \cdot 7$ & $101 \cdot 7$ & $34 \cdot 1$ & 0.05 & $21 \cdot 1$ & 9.9 & 0.08 & 29.5 & $50 \cdot 1$ \\
\hline & 182 & $12 \cdot 8$ & 89.6 & 34.0 & 0.08 & $15 \cdot 4$ & $4 \cdot 8$ & 0.09 & $21 \cdot 8$ & 57.5 \\
\hline \multirow[t]{7}{*}{ M1.5 } & 0.5 & $12 \cdot 2$ & $336 \cdot 0$ & $142 \cdot 6$ & $0 \cdot 18$ & $93 \cdot 7$ & $109 \cdot 7$ & 0.20 & $25 \cdot 2$ & $16 \cdot 6$ \\
\hline & 1 & $12 \cdot 3$ & 333.3 & $141 \cdot 2$ & $0 \cdot 17$ & $106 \cdot 9$ & $116 \cdot 1$ & 0.13 & $129 \cdot 3$ & 18.5 \\
\hline & 7 & $12 \cdot 5$ & $186 \cdot 6$ & $63 \cdot 3$ & $0 \cdot 12$ & $60 \cdot 7$ & $41 \cdot 1$ & 0.14 & 78.0 & $31 \cdot 3$ \\
\hline & 14 & $12 \cdot 6$ & 143.6 & $46 \cdot 7$ & 0.11 & 41.9 & $17 \cdot 3$ & $0 \cdot 10$ & $69 \cdot 4$ & 36.0 \\
\hline & 28 & $12 \cdot 5$ & $93 \cdot 3$ & $32 \cdot 5$ & 0.06 & $22 \cdot 6$ & $6 \cdot 9$ & 0.07 & $57 \cdot 6$ & $32 \cdot 1$ \\
\hline & 56 & $12 \cdot 6$ & 89.7 & $30 \cdot 4$ & 0.07 & $20 \cdot 0$ & $7 \cdot 4$ & 0.09 & $41 \cdot 4$ & $36 \cdot 8$ \\
\hline & 182 & $12 \cdot 7$ & 83.0 & $30 \cdot 1$ & 0.09 & 15.9 & $6 \cdot 6$ & 0.13 & $19 \cdot 2$ & 49.0 \\
\hline \multirow[t]{7}{*}{ M2 } & 0.5 & $10 \cdot 0^{\mathrm{a}}$ & 289.5 & $116 \cdot 1$ & $9 \cdot 2$ & 83.6 & $174 \cdot 1$ & 0.00 & $10 \cdot 6$ & 0.1 \\
\hline & 1 & $11 \cdot 1$ & 323.8 & $119 \cdot 2$ & 3.90 & $103 \cdot 2$ & $184 \cdot 2$ & 0.02 & $9 \cdot 0$ & $1 \cdot 3$ \\
\hline & 7 & $10 \cdot 6$ & $135 \cdot 8$ & $41 \cdot 2$ & $5 \cdot 83$ & 38.5 & $92 \cdot 8$ & 0.01 & $2 \cdot 1$ & 0.4 \\
\hline & 14 & 11.4 & $92 \cdot 1$ & 30.0 & 1.47 & $26 \cdot 1$ & 59.5 & 0.04 & 4.5 & 2.6 \\
\hline & 28 & 11.9 & 79.5 & 24.6 & 0.24 & 21.0 & 34.7 & 0.06 & $11 \cdot 3$ & 8.8 \\
\hline & 56 & $12 \cdot 1$ & $65 \cdot 7$ & $20 \cdot 3$ & $0 \cdot 18$ & $19 \cdot 3$ & 25.9 & 0.08 & $9 \cdot 2$ & $12 \cdot 4$ \\
\hline & 182 & 11.9 & $69 \cdot 2$ & 21.9 & $0 \cdot 27$ & $18 \cdot 3$ & 17.9 & 0.07 & $1 \cdot 2$ & 7.9 \\
\hline
\end{tabular}

${ }^{\text {a }}$ Repetition of the measurements resulted in $\mathrm{pH} 9.6$

and the species should not form or dissolve until equilibrium is restored.

3. $\mathrm{SI}=\log _{10}\left(\frac{\mathrm{IAP}}{K_{\mathrm{sp}}}\right)$

In the system with the highest gypsum addition (M2), gypsum remained near saturation during the first weeks, consistent with its presence observed by XRD. All systems had positive SI for ettringite through $14 \mathrm{~d}$ of hydration, and for the pastes with added gypsum the oversaturation increased with added gypsum content. M0 1 was the only paste to have significant levels of oversaturation with regard to monosulfate; again in agreement with the presence of monosulfate observed in these samples (Figures 5 and 6). Oversaturation with regards to $\mathrm{AH}_{3}$ generally increased with increasing added gypsum and became more persistent into later ages. Note: during the first hours to days generally very soluble amorphous $\mathrm{AH}_{3}$ is formed, which slowly becomes more ordered, which is accompanied by a decrease in solubility (Lothenbach et al., 2012). Gibbsite, the crystalline form of $\mathrm{AH}_{3}$, forms extremely slowly at ambient conditions. Thus, the decrease of the solubility of $\mathrm{AH}_{3}$ with time was considered in the calculations as detailed in the earlier section entitled ' $\mathrm{X}$-ray diffraction and thermogravimetric analysis'. $\mathrm{CAH}_{10}$ was supersaturated most markedly at early ages in M0.1 and M1, at ages which precede its transient appearance in the XRD patterns. In M0 1, strätlingite showed the highest degree of oversaturation at early ages. In the pastes with added gypsum, the SI of strätlingite tended to decrease with increasing additional gypsum, which is consistent with the dilution of belite, denser paste microstructures inhibiting belite dissolution, and the reduced stability of AFm phases in the presence of gypsum as discussed in the section entitled 'Hydration'.

\section{Stress from crystallisation}

The maximum crystallisation pressure, $P_{\mathrm{c}}$, that can be developed due to a given oversaturation of a phase can be calculated according to Equation 4, where the universal gas constant, $R=8 \cdot 314 \mathrm{~J} /(\mathrm{mol} \cdot \mathrm{K})$, absolute temperature, $T=293 \cdot 15 \mathrm{~K}, V_{\mathrm{m}}$ is the phase's molar volume and $K_{\mathrm{sp}}$ is the phase's solubility product.

4. $\quad P_{\mathrm{c}}=\frac{\mathrm{RT}}{V_{\mathrm{m}}} \ln \frac{\mathrm{IAP}}{K_{\mathrm{sp}}}$ 
Table 4. Saturation indices

\begin{tabular}{|c|c|c|c|c|c|c|c|c|}
\hline & Time: d & Ettringite & Monosulfate & $\mathrm{AH}_{3}{ }^{\mathrm{a}}$ & $\mathrm{CAH}_{10}$ & Strätlingite & Gypsum & C-S-H \\
\hline \multirow[t]{7}{*}{ M0.1 } & 0.5 & 1.9 & 1.4 & 0.2 & 1.2 & $2 \cdot 3$ & $-3 \cdot 0$ & $-2 \cdot 5$ \\
\hline & 1 & $2 \cdot 1$ & 1.0 & 0.7 & 1.4 & $2 \cdot 5$ & $-2 \cdot 8$ & $-2 \cdot 4$ \\
\hline & 7 & 1.5 & $0 \cdot 1$ & 0.0 & $-0 \cdot 1$ & 1.6 & $-2 \cdot 6$ & -1.9 \\
\hline & 14 & 0.3 & -0.7 & -0.2 & -0.7 & 0.9 & $-2 \cdot 8$ & -1.9 \\
\hline & 28 & -2.5 & $-2 \cdot 4$ & -0.3 & $-1 \cdot 2$ & -0.4 & $-3 \cdot 4$ & $-2 \cdot 6$ \\
\hline & 56 & $-1 \cdot 4$ & $-2 \cdot 0$ & -0.4 & $-1 \cdot 5$ & -0.5 & $-3 \cdot 0$ & $-2 \cdot 5$ \\
\hline & 182 & -0.5 & $-0 \cdot 8$ & -0.3 & $-1 \cdot 0$ & 0.7 & $-3 \cdot 2$ & $-1 \cdot 9$ \\
\hline \multirow[t]{7}{*}{ M1 } & 0.5 & $1 \cdot 1$ & $-0 \cdot 1$ & 0.5 & 0.9 & $2 \cdot 2$ & $-2 \cdot 7$ & $-2 \cdot 1$ \\
\hline & 1 & 0.9 & $-0 \cdot 1$ & 0.6 & 1.0 & $2 \cdot 1$ & $-2 \cdot 8$ & $-2 \cdot 3$ \\
\hline & 7 & 1.4 & $0 \cdot 1$ & $0 \cdot 2$ & $0 \cdot 3$ & 1.9 & $-2 \cdot 7$ & -1.9 \\
\hline & 14 & 0.5 & -0.6 & $0 \cdot 1$ & $-0 \cdot 1$ & 1.5 & $-2 \cdot 8$ & -1.9 \\
\hline & 28 & $-2 \cdot 5$ & $-2 \cdot 4$ & $0 \cdot 2$ & -0.5 & 0.6 & $-3 \cdot 4$ & $-2 \cdot 2$ \\
\hline & 56 & $-1 \cdot 1$ & $-1 \cdot 7$ & $0 \cdot 1$ & $-0 \cdot 6$ & 0.8 & $-3 \cdot 0$ & $-2 \cdot 0$ \\
\hline & 182 & -0.9 & $-1 \cdot 4$ & 0.0 & -0.7 & 0.9 & $-3 \cdot 1$ & $-1 \cdot 8$ \\
\hline \multirow[t]{7}{*}{ M1.5 } & 0.5 & $1 \cdot 7$ & $-1 \cdot 0$ & $-0 \cdot 2$ & -0.6 & $1 \cdot 2$ & -1.9 & $-1 \cdot 5$ \\
\hline & 1 & $1 \cdot 4$ & $-1 \cdot 2$ & 1.0 & $0 \cdot 8$ & $2 \cdot 0$ & $-2 \cdot 0$ & -1.9 \\
\hline & 7 & 1.0 & $-1 \cdot 1$ & 0.7 & 0.4 & 1.9 & $-2 \cdot 3$ & $-1 \cdot 7$ \\
\hline & 14 & $1 \cdot 1$ & -0.5 & 0.5 & 0.4 & 1.9 & -2.5 & $-1 \cdot 8$ \\
\hline & 28 & $-1 \cdot 5$ & $-2 \cdot 1$ & 0.7 & $0 \cdot 1$ & $1 \cdot 3$ & $-3 \cdot 0$ & $-2 \cdot 0$ \\
\hline & 56 & -0.9 & $-1 \cdot 7$ & 0.4 & $-0 \cdot 2$ & $1 \cdot 3$ & $-3 \cdot 0$ & $-1 \cdot 8$ \\
\hline & 182 & -0.6 & $-1 \cdot 4$ & $0 \cdot 1$ & -0.8 & $1 \cdot 0$ & $-2 \cdot 9$ & $-1 \cdot 6$ \\
\hline \multirow[t]{7}{*}{ M2 } & 0.5 & 1.6 & $-4 \cdot 9$ & 1.9 & 0.3 & $-6 \cdot 9$ & -0.1 & $-9 \cdot 5$ \\
\hline & 1 & $3 \cdot 1$ & $-2 \cdot 6$ & 0.9 & $-0 \cdot 2$ & 0.6 & -0.4 & -1.9 \\
\hline & 7 & $2 \cdot 7$ & $-3 \cdot 4$ & 0.7 & $-1 \cdot 1$ & -0.6 & -0.3 & $-2 \cdot 2$ \\
\hline & 14 & 1.0 & -3.9 & 0.8 & -0.9 & 0.0 & -0.9 & $-1 \cdot 8$ \\
\hline & 28 & -0.5 & $-3 \cdot 6$ & 0.7 & -0.8 & 0.2 & $-1 \cdot 8$ & $-1 \cdot 8$ \\
\hline & 56 & -0.8 & $-3 \cdot 5$ & 0.5 & $-1 \cdot 1$ & 0.2 & -1.9 & -1.7 \\
\hline & 182 & 0.3 & -2.5 & -0.8 & $-2 \cdot 6$ & -0.8 & -1.9 & $-1 \cdot 6$ \\
\hline
\end{tabular}

${ }^{\text {a }} \mathrm{A}$ decrease of $\mathrm{AH}_{3}$ solubility with time is considered as detailed in the section entitled ' $\mathrm{X}$-ray diffraction and thermogravimetric analysis'

The maximum crystallisation pressure does not account for the geometry or size of the pore or crystal, but provides an upper bound on crystallisation pressure that would be produced from the growth of relatively large crystals. The calculated maximum crystallisation pressures are presented in Figure 8. Interestingly, $\mathrm{AH}_{3}$ is calculated to produce the highest crystallisation pressures in all systems and produces the highest crystallisation pressure calculated in this study, $337 \mathrm{MPa}$, in $\mathrm{M} 2$ at $0.5 \mathrm{~d}$. The high crystallisation pressures calculated for $\mathrm{AH}_{3}$ are a result of its relatively high SI and its low molar volume, $V_{\mathrm{m}}=32 \mathrm{~cm}^{3} / \mathrm{mol}$. Strätlingite and $\mathrm{CAH}_{10}$ produce higher crystallisation pressures in the pastes with less added gypsum, which is consistent with the XRD data showing the pastes with less gypsum produced more of those phases. Monosulfate produced its highest crystallisation pressure in the paste without added gypsum between 0.5 and $7 \mathrm{~d}$ and tended to produce very low or zero crystallisation pressure in the pastes with added gypsum. Ettringite produced positive crystallisation pressure in all systems through $14 \mathrm{~d}$; however, the calculated crystallisation pressure was often lower than the crystallisation pressures calculated for $\mathrm{AH}_{3}$, strätlingite and $\mathrm{CAH}_{10}$, despite ettringite having some of the highest SI. Ettringite's relatively lower crystallisation pressure is due to its modest oversaturation and its large molar volume, $V_{\mathrm{m}}=707 \mathrm{~cm}^{3} / \mathrm{mol}$. However, the volume of the crystallising phase and the geometry of the pore in which the crystallisation is occurring affect the amount of force that the crystallising phase can exert on the surrounding paste. The role that spatial effects play in the forces that can be generated from phases crystallising will be discussed subsequently.

The hydrostatic tensile stress, $\sigma_{\text {cyl }}$, generated from crystallisation can be calculated for cylindrical pore geometries according to Equation 5 (Chaunsali and Mondal, 2015b), where $P$ is the crystallisation pressure and $\phi$ is the volume fraction of crystallising phase. Inputting $P_{\mathrm{c}}$ from Equation 4 for $P$ gives an upper bound on the hydrostatic tensile stress.

5. $\sigma_{\mathrm{cyl}}=P \frac{2}{3}\left(\frac{\phi}{1-\phi}\right)$

Figure 9 presents the maximum hydrostatic tensile stress assuming cylindrical pores calculated using the phase volumes determined by thermodynamic modelling utilising the QXRD data to account for the hydration reaction kinetics combined with the SI determined from the expressed pore solutions. The phase volumes from thermodynamic modelling were selected over the phase volumes from QXRD to overcome the poor quantification of AFm phases, which form solid solutions, and 


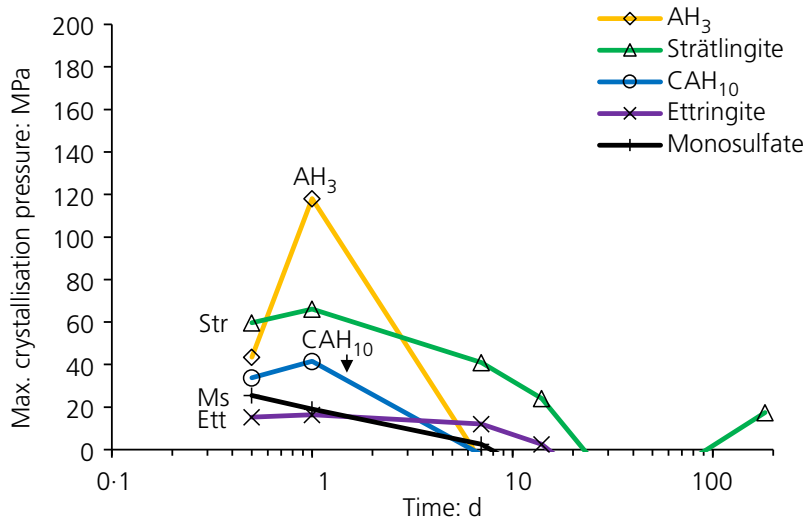

(a)

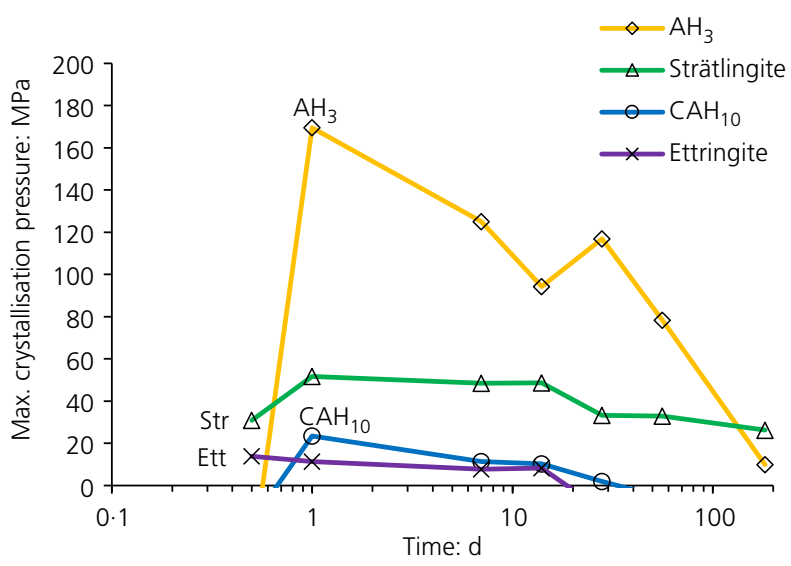

(c)

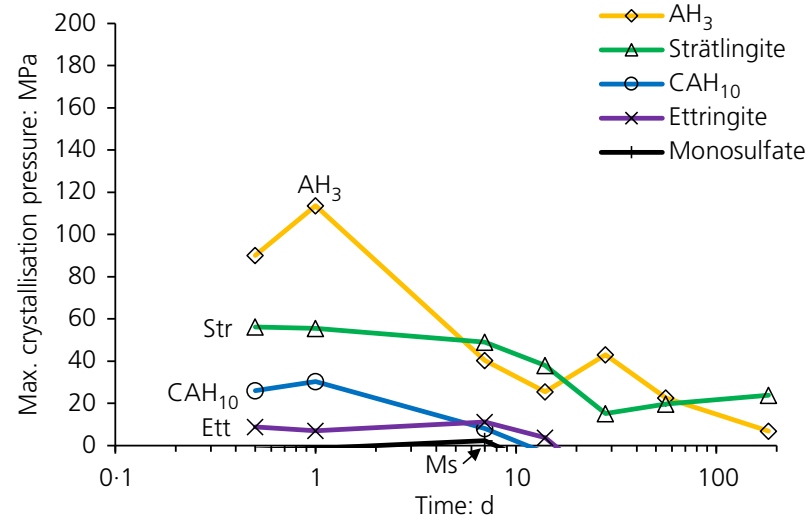

(b)

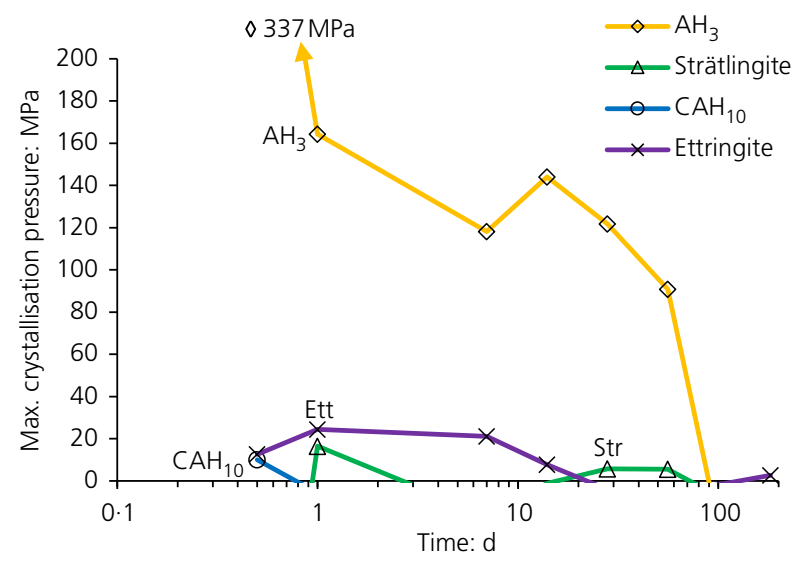

(d)

Figure 8. Maximum crystallisation pressures, $P_{\mathrm{c}}$ calculated in the CSA cement pastes: (a) M0.1; (b) M1; (c) M1.5; (d) M2

$\mathrm{AH}_{3}$, which is poorly crystalline at early ages of hydration. As was the case with the maximum crystallisation pressure, $\mathrm{AH}_{3}$ tended to produce the highest hydrostatic tensile stresses in all of the pastes. In $\mathrm{M} 0 \cdot 1, \mathrm{AH}_{3}$ is calculated to produce the greatest tensile stress $(8.4 \mathrm{MPa})$ at $1 \mathrm{~d}$, followed by monosulfate $(3.9 \mathrm{MPa})$ at $0.5 \mathrm{~d}$ and strätlingite at $182 \mathrm{~d}(0.8 \mathrm{MPa})$. In M1 and M1.5, ettringite produced the second highest hydrostatic tensile stresses and strätlingite continued to produce relatively lower hydrostatic tensile stresses, which tended to increase modestly with time to a maximum of $\sim 0.5 \mathrm{MPa}$ at $182 \mathrm{~d}$. In $\mathrm{M} 2$, the trend of ettringite producing increasing hydrostatic tensile stresses with increasing amounts of gypsum continued with a maximum of $11.6 \mathrm{MPa}$ at $7 \mathrm{~d}$. All pastes have phases producing maximum hydrostatic tensile stresses which exceed the measured $1 \mathrm{~d}$ tensile strengths of the pastes, which are 0.7 , $0 \cdot 9,1 \cdot 1$ and $1.2 \mathrm{MPa}$ for $\mathrm{M} 0 \cdot 1, \mathrm{M} 1, \mathrm{M} 1 \cdot 5$ and $\mathrm{M} 2$, respectively. Accordingly, all pastes cured in water experienced expansion in this study.

As crystals become smaller, their curvature and solubility increases, and when calculating the pressure that they can exert during crystallisation, their interfacial free energy must be taken into account. The net crystallisation pressure, $\Delta P$, that a growing crystal can exert on the pore wall is given in Equation 6 for cylindrical pores, where $\gamma_{\mathrm{cl}}$ is the interfacial free energy between the crystal and the liquid; $r_{\mathrm{p}}$ is the pore radius; and $\delta$ is the water layer separating the growing crystal and the pore wall. The radius of the crystal $r_{\mathrm{c}}$ equals $r_{\mathrm{p}}-\delta$. In this study, $\delta$ is assumed to equal $2 \mathrm{~nm}$ and $\gamma_{\mathrm{cl}}$ is assumed to be $0 \cdot 1 \mathrm{~J} / \mathrm{m}^{2}$, which is consistent with assumptions made in prior studies (Flatt and Scherer, 2008; Scherer, 2004).

6. $\Delta P=\frac{\mathrm{RT}}{V_{\mathrm{m}}} \ln \frac{\mathrm{IAP}}{K_{\mathrm{sp}}}-\gamma_{\mathrm{cl}} \frac{1}{r_{\mathrm{p}}-\delta}=\frac{\mathrm{RT}}{V_{\mathrm{m}}} \ln \frac{\mathrm{IAP}}{K_{\mathrm{sp}}}-\gamma_{\mathrm{cl}} \frac{1}{r_{\mathrm{c}}}$

Setting Equation 6 to zero and solving for $r_{\mathrm{p}}$ produces Equation 7 and gives the minimum pore radius (assuming cylindrical geometry) in which a crystal can grow given the ionic concentration of the pore fluid at that time.

7. $r_{\mathrm{p}}=\frac{V_{\mathrm{m}} \gamma_{\mathrm{cl}}}{\mathrm{RT}}\left(\ln \frac{\mathrm{IAP}}{K_{\mathrm{sp}}}\right)^{-1}+\delta$ 


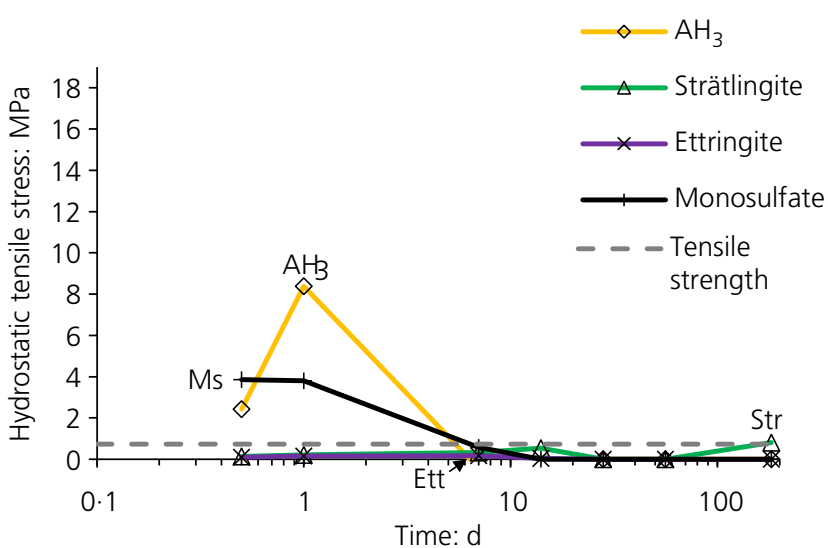

(a)

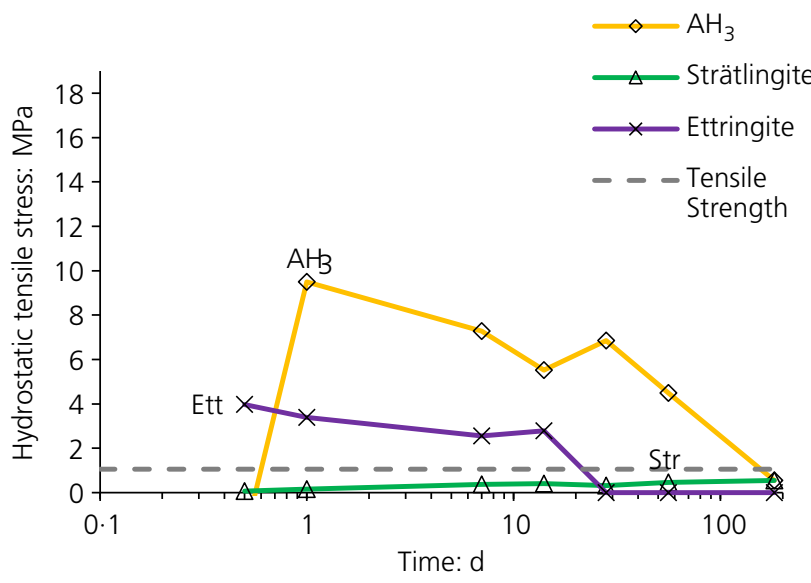

(c)

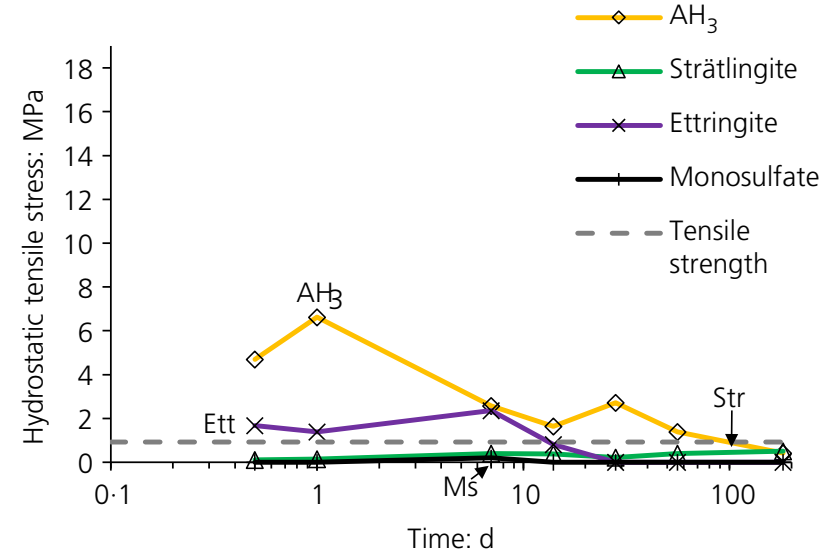

(b)

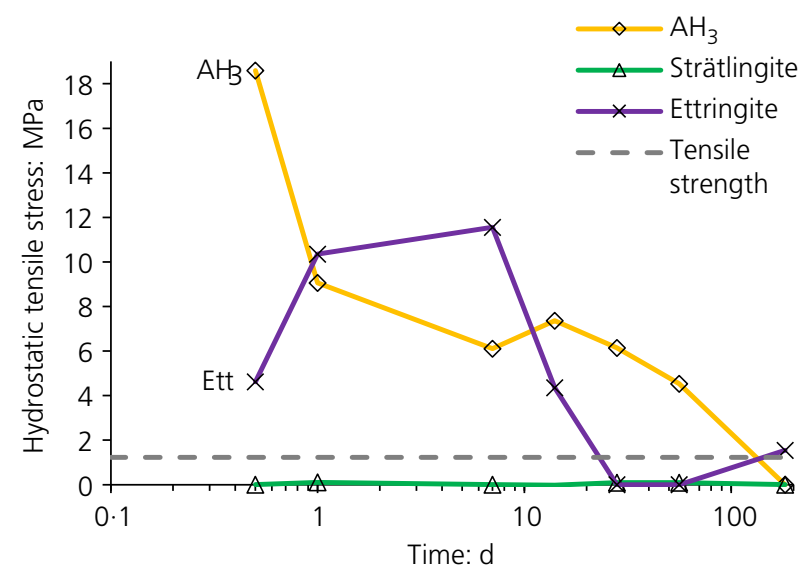

(d)

Figure 9. Maximum hydrostatic tensile stresses calculated in CSA cement pastes: (a) M0.1; (b) M1; (c) M1.5; (d) M2. The 1 d tensile strength for each paste is the gray dashed horizontal line

Crystals will tend to form in free space where they do not need to exert expansive forces. Accordingly, the geometry of the pores and the diffusion of ions in the pore solution play an important role in the ability of a hydrated cement paste to develop crystallisation pressure. At a given crystallisation pressure or oversaturation only pores with at least the minimum pore radius, $r_{\mathrm{p}}$, can be filled, while smaller pores cannot be filled because more oversaturation would be needed. The pressure exerted can be estimated from the difference between the percolation pore radius from MIP measurements and from the minimum pore radius needed for the growth of the oversaturated solid (Bizzozero et al., 2014), according to Equation 6. If the percolation pore radius in the hydrated cement, $r_{\mathrm{p}}$, is smaller than the minimum pore radius needed for the growth of the oversaturated solid, no damage is expected as no solid can form; damage can be expected if the pore size is larger than the minimum pore radius but less than the percolation pore radius because pores above that value are considered large pores, such as entrapped air voids, where crystals may grow freely without exerting pressure on the pore walls.
Mercury intrusion porimetry was utilised to estimate values for radii of the pore network. MIP has some known limitations, which are that the intrusion pressure measures the volume of pores with that pore entrance (not the actual pore volume with that radius), pores are not perfect cylinders or spheres (which affects the pore radius calculation for a given pressure) and MIP may induce damage during testing, thereby altering the porosity. Figure 10 shows the cumulative pore volume for M2 at 7, 14 and $28 \mathrm{~d}$ and shows the determination of the percolation pore radius for M2 at $7 \mathrm{~d}$. The intersection of the two tangents was utilised to define the percolation pore radius. This was done to be consistent with prior research by Bizzozero et al. (2014). As can be seen from Figure 10, the hydration of CSA cement continued to refine the porosity of the cement paste through $28 \mathrm{~d}$, reducing both the total pore volume and pore radii.

Table 5 gives the percolation pore radii determined from MIP for all pastes and minimum pore radius in which crystals of each phase can grow between at 7, 14 and $28 \mathrm{~d}$ of hydration. 


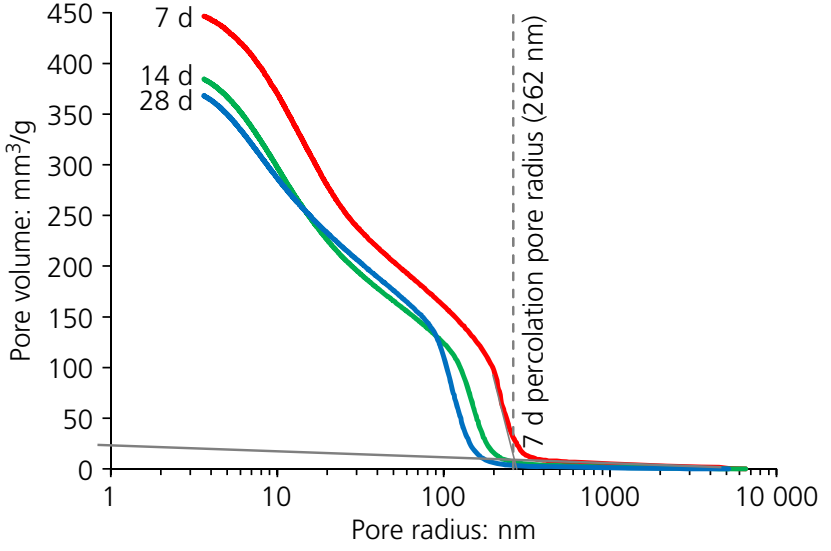

Figure 10. Cumulative pore volume for $M 2$ at 7, 14 and $28 \mathrm{~d}$, showing determination of the percolation pore radius for $\mathrm{M} 2$ at $7 \mathrm{~d}$

Comparing the percolation pore radii at $7 \mathrm{~d}, \mathrm{M} 0 \cdot 1$ and $\mathrm{M} 2$ have higher values for their percolation pore radii compared to M1 and M1.5 for different reasons. Added calcium sulfate accelerates the hydration of ye'elimite and formation of ettringite, which reduces the porosity, which explains the decrease in the percolation pore radius from M0 1 to M1. However, added gypsum also leads to additional expansion, which is accompanied by cracking, which explains why the percolation pore radius increases from M1.5 to M2. As hydration proceeds and the rate of expansion declines, M2 has a reduction in total porosity and the percolation pore radius. Table 5 also shows that, when the SI for a phase is higher, it can grow into smaller pores. For instance, in M2 at $7 \mathrm{~d}$ when the SI of ettringite is $2 \cdot 7$, ettringite crystals can grow into pores with radii as small as $7 \mathrm{~nm}$, but at $14 \mathrm{~d}$ when the SI of ettringite is $1 \cdot 0$, ettringite can grow into pores with radii as small as $15 \mathrm{~nm}$. By $28 \mathrm{~d}$, the SI for ettringite was negative for all pastes, indicating further growth of ettringite is not expected at that age. $\mathrm{AH}_{3}$ can grow into the smallest pores $(3 \mathrm{~nm})$ of any of the phases calculated in this study due to its small molar volume. In M1 at $7 \mathrm{~d}$, the minimum pore radius for monosulfate growth $(45 \mathrm{~nm})$ exceeds the percolation pore radius $(17 \mathrm{~nm})$, indicating that under the given oversaturation for monosulfate at that time, monosulfate is not expected to form in the percolated porosity where it can exert pressure.

The role of porosity and crystal size on the net pressures that crystals can exert on pore walls was determined using $\Delta P$ from Equation 6 in Equation 5 for $P$, utilising MIP data for pore size distributions and thermodynamically calculated phase assemblages and SI. The calculated net hydrostatic tensile stresses were a volume weighted average based on the porosity between the percolation and minimum pore radii. Comparing

Table 5. Percolation pore radius from MIP, minimum pore radius from Equation 7, and net hydrostatic tensile stress utilising Equations 5 and 6 with MIP porosity data

\begin{tabular}{|c|c|c|c|c|c|c|c|c|c|}
\hline & \multirow[b]{2}{*}{ Time: $\mathbf{d}$} & \multicolumn{4}{|c|}{ Minimum pore radius: $\mathbf{n m}$} & \multicolumn{4}{|c|}{ Hydrostatic tensile stress: $\mathrm{MPa}$} \\
\hline & & M0.1 & M1 & M1.5 & M2 & M0.1 & M1 & M1.5 & M2 \\
\hline \multirow[t]{3}{*}{ Ettringite } & 7 & 10 & 11 & 15 & 7 & 0.1 & 0.5 & 0.2 & 9 \\
\hline & 14 & 42 & 28 & 14 & 15 & 0.02 & $\mathrm{a}$ & $a$ & 3 \\
\hline & 28 & b & b & $\mathrm{b}$ & $\mathrm{b}$ & & a & a & b \\
\hline \multirow[t]{3}{*}{ Monosulfate } & 7 & 41 & 45 & b & b & $0 \cdot 4$ & c & b & b \\
\hline & 14 & $\mathrm{~b}$ & $\mathrm{~b}$ & b & $\mathrm{b}$ & b & a & a & b \\
\hline & 28 & b & b & $\mathrm{b}$ & $\mathrm{b}$ & $\mathrm{b}$ & a & a & $\mathrm{b}$ \\
\hline \multirow{3}{*}{$\mathrm{AH}_{3}$} & 7 & b & 4 & 3 & 3 & $\mathrm{~b}$ & 2 & 6 & 6 \\
\hline & 14 & b & 6 & 3 & 3 & b & a & a & 7 \\
\hline & 28 & b & 4 & 3 & 3 & $\mathrm{~b}$ & a & a & 6 \\
\hline \multirow{3}{*}{$\mathrm{CAH}_{10}$} & 7 & b & 14 & 11 & b & b & a & a & b \\
\hline & 14 & $\mathrm{~b}$ & b & 12 & b & $\mathrm{b}$ & a & a & $\mathrm{b}$ \\
\hline & 28 & $\mathrm{~b}$ & b & 53 & b & b & a & a & b \\
\hline \multirow[t]{4}{*}{ Strätlingite } & 7 & 4 & 4 & 4 & $\mathrm{~b}$ & $0 \cdot 3$ & $0 \cdot 3$ & 0.3 & $\mathrm{~b}$ \\
\hline & 14 & 6 & 5 & 4 & $\mathrm{~b}$ & 0.5 & a & a & $\mathrm{b}$ \\
\hline & 28 & b & 9 & 5 & 20 & b & a & a & 0.07 \\
\hline & & \multicolumn{8}{|c|}{ Percolation pore radius: $\mathbf{n m}$} \\
\hline \multicolumn{2}{|l|}{ Time: d } & \multicolumn{2}{|l|}{$\mathrm{M} 0 \cdot 1$} & \multicolumn{2}{|c|}{ M1 } & \multicolumn{3}{|c|}{ M1.5 } & M2 \\
\hline \multirow{3}{*}{\multicolumn{2}{|c|}{$\begin{array}{l}7 \\
14 \\
28\end{array}$}} & \multicolumn{2}{|l|}{271} & \multicolumn{2}{|l|}{17} & \multicolumn{3}{|c|}{17} & 262 \\
\hline & & \multicolumn{2}{|l|}{304} & \multicolumn{2}{|c|}{ a } & \multicolumn{3}{|c|}{$\mathrm{a}$} & 183 \\
\hline & & \multicolumn{2}{|l|}{263} & \multicolumn{2}{|l|}{ a } & \multicolumn{2}{|c|}{ a } & & 143 \\
\hline
\end{tabular}

${ }^{a}$ Not measured

${ }^{\mathrm{b}}$ Negative SI

${ }^{\mathrm{C}}$ Minimum pore radius below percolation pore radius 
the values for the net hydrostatic tensile stresses in Table 5 to the maximum hydrostatic tensile stresses in Figure 9, the effect of small pores reducing the hydrostatic tensile stresses developed becomes apparent. For instance in M2 at $7 \mathrm{~d}$, ettringite is calculated to have a net and maximum hydrostatic tensile stress of 8.9 and $11.6 \mathrm{MPa}$, respectively. Likewise, $\mathrm{AH}_{3}$ is calculated to have a net and maximum hydrostatic tensile stress of $5 \cdot 8$ and $6 \cdot 1 \mathrm{MPa}$, respectively, at $7 \mathrm{~d}$ in $\mathrm{M} 2$.

\section{Discussion}

Historically, expansion in CSA cement pastes has always been attributed to ettringite, whether it be crystalline or 'colloidal'. Accordingly, this study also found that CSA cement pastes with higher ettringite production and supersaturation had greater amounts of expansion. However, unlike prior studies, this study also considered other crystalline hydrates like monosulfate, $\mathrm{CAH}_{10}, \mathrm{AH}_{3}$ and strätlingite. The calculations show that at early ages and low added calcium sulfate content (M0 1 at $0 \cdot 5-1 \mathrm{~d})$, monosulfate could produce a maximum hydrostatic tensile stress of $\sim 4 \mathrm{MPa}$. At later ages and lower added calcium sulfate contents, strätlingite was calculated to produce a maximum hydrostatic tensile stress of $\sim 0 \cdot 5-1 \mathrm{MPa}$. Moreover, $\mathrm{AH}_{3}$ was calculated to produce higher hydrostatic tensile stresses than ettringite more often than not. In M2 at $0.5 \mathrm{~d}$, the maximum hydrostatic tensile stress produced by ettringite and $\mathrm{AH}_{3}$ was 4.6 and $18.6 \mathrm{MPa}$, respectively; however, by $7 \mathrm{~d}$ in $\mathrm{M} 2$ this had reversed and ettringite was calculated to produce a larger maximum hydrostatic tensile stress than $\mathrm{AH}_{3}$.

This raises some important questions. First, is ettringite solely responsible for CSA cement expansion, as prior research has considered, or is expansion due to the sum of all the hydrostatic pressures developed by the different crystallising hydrates? For crystal growth theory to be correct, one would assert that any crystallising phase must be considered to have the potential to exert pressure on the surrounding matrix given the correct circumstances. Otherwise, ettringite is given an almost mythical status to create expansion while ignoring other crystalline phases' potential role in the expansion mechanism. Moreover, fundamental scientific data such as the actual interfacial free energies of the various crystalline hydrates need to be determined in order to better understand how crystal size affects different hydrates differently.

In this study, $\mathrm{AH}_{3}$ was often calculated to generate some of the highest maximum hydrostatic tensile stresses; however, these calculations do not take into consideration the role of the crystal size on decreasing the net hydrostatic tensile stress which can be generated. Moreover, when utilising MIP values for the porosity in which $\mathrm{AH}_{3}$ can grow, the assumption is that the crystals are growing to a size to fill the pore radius (to within a $2 \mathrm{~nm}$ water layer surrounding the crystal), thus enabling $\mathrm{AH}_{3}$ to exert pressure on the pore walls. However, although $\mathrm{AH}_{3}$ can form in clusters of several microns in size, recent research has shown through pair distribution function (PDF) analysis that the actual crystallites are approximately $3 \mathrm{~nm}$ in diameter (Cuesta et al., 2017b). If $r_{\mathrm{c}}=1.5 \mathrm{~nm}$ $\left(r_{\mathrm{p}}=3.5 \mathrm{~nm}\right)$ is utilised with Equations 5 and 6 for $\mathrm{AH}_{3}$ in $\mathrm{M} 2$ at $7 \mathrm{~d}$, then the net hydrostatic tensile stress calculated is $2.7 \mathrm{MPa}$ (compared to $5.8 \mathrm{MPa}$ using porosity from MIP). However, that stress would only develop in pores of that radius. In larger pores, nanocrystalline $\mathrm{AH}_{3}$ would be free to form without exerting pressure on the pore walls, and in smaller pores the net hydrostatic tensile stress would be reduced below $2.7 \mathrm{MPa}$ due to the increasing role of small crystal size reducing the net pressure that $\mathrm{AH}_{3}$ can exert. As a consequence of $\mathrm{AH}_{3}$ being nanocrystalline and having a small pore range where it can exert pressure, its role in expansion is expected to be dramatically reduced compared to what would be calculated using MIP data and upper bound assumptions for hydrostatic tensile stress and crystallisation pressure.

Certain factors were found to strongly affect the hydrostatic tensile stresses calculated. (a) Using a spherical geometry instead of cylindrical increases the hydrostatic tensile stresses calculated by $50 \%$. (b) The pore solution, porosity and phase assemblage change with time; at less than 6 months of hydration when their values are changing rapidly, calculating the hydrostatic tensile stress developed at a particular point in time utilising values from a different time would create large errors. (c) The distribution of pore radii utilised when considering the interfacial free energy at the crystal-liquid interface can affect the hydrostatic tensile stresses calculated by $\sim 25 \%$, depending on whether a simple average or a weighted average is utilised.

Future research should try to determine the interfacial free energies for the various hydration products in CSA cements, which may also help to explain why some hydrates exert more pressure than others. Finally, future improved or new techniques (such as phase resolved tomography or ptychography) may resolve where hydration products are depositing over time, which would greatly enhance understanding of the expansion mechanism in CSA cement pastes.

\section{Conclusions}

This study expanded on prior studies investigating the expansion mechanism of CSA cement pastes. Four different molar ratios of gypsum to ye'elimite ranging from $0 \cdot 1$ to 2 were utilised and the expansion, mass gain, phase assemblage and pore solution were monitored at intervals over $182 \mathrm{~d}$. The results of the study can be summarised as follows.

(a) Mass gain. Mass gain during water curing increased with increasing gypsum content due to the increased production of hydration products and water absorbed in cracks and microcracks.

(b) Expansion. Expansion of CSA cement pastes increased with increasing gypsum in tests with both externally 
supplied water and without. When cured in water, the CSA cement paste with a molar ratio of $2: 1$ gypsum to ye'elimite had a much faster rate and magnitude of expansion; accordingly, it cracked severely after $1 \mathrm{~d}$ of water curing.

(c) Hydration. As the gypsum content in the CSA cement pastes increased, ettringite production increased and monosulfate, $\mathrm{CAH}_{10}$ and strätlingite production decreased due to both a dilution of the clinker phases and, more predominantly, a faster rate of ettringite production densifying the paste microstructure, limiting the further reaction of anhydrous clinker phases.

(d) Pore solution. Increasing gypsum content raised the calcium and sulfate ion concentrations at early ages, but lowered the aluminate and silicate ion concentrations. Ettringite buffers the pore solution at a lower $\mathrm{pH}$ value than monosulfate, so the CSA cement paste with a stoichiometric amount of gypsum for ettringite production had a lower $\mathrm{pH}$ of $10 \cdot 0$ at $0.5 \mathrm{~d}$ and $12 \cdot 1$ at $56 \mathrm{~d}$, comparted to a $\mathrm{pH}$ of 12.7 at both ages for the CSA cement, which had a molar ratio of $1: 1$ gypsum to ye'elimite, which would also produce monosulfate in addition to ettringite. All CSA cement pastes had a positive SI for ettringite through $14 \mathrm{~d}$ and pastes with added gypsum had positive SI for $\mathrm{AH}_{3}$ through $56 \mathrm{~d}$. The CSA cement paste without added gypsum had a positive SI for monosulfate through $7 \mathrm{~d}, \mathrm{CAH}_{10}$ through $1 \mathrm{~d}$ and strätlingite through $14 \mathrm{~d}$. The CSA cement pastes with $1: 1$ and $1: 1.5$ molar ratios of gypsum to ye'elimite had positive SI for $\mathrm{CAH}_{10}$ at different times through $28 \mathrm{~d}$ and positive SI for strätlingite through 182 d. Positive SI for crystallising phases can be converted into crystallisation pressure.

(e) Crystallisation pressure. $\mathrm{AH}_{3}$, strätlingite, $\mathrm{CAH}_{10}$, monosulfate and ettringite were all calculated to produce significant crystallisation pressures. $\mathrm{AH}_{3}$ was consistently calculated to produce some of the highest crystallisation pressures (up to $337 \mathrm{MPa}$ ). Crystallisation pressures for strätlingite, $\mathrm{CAH}_{10}$ and monosulfate increased with decreasing gypsum content. All CSA cement pastes were calculated to produce positive crystallisation pressures for ettringite, with the CSA cement paste highest in gypsum content producing the greatest crystallisation pressure for ettringite.

( $f$ ) Hydrostatic tensile stress. When calculating the hydrostatic tensile stresses, strätlingite and $\mathrm{CAH}_{10}$ produced much lower stresses compared to their maximum possible crystallisation pressures due to their low volumes. Contrarily, in the pastes with added gypsum, $\mathrm{AH}_{3}$ and ettringite produce the highest hydrostatic tensile stress, which increase with added gypsum. In the CSA cement paste without added gypsum, monosulfate and $\mathrm{AH}_{3}$ are calculated to produce the highest hydrostatic tensile stresses, but the hydrostatic tensile stresses produced by strätlingite are calculated to increase with time as belite hydrates and releases calcium and silicate ions. All CSA cement pastes in this study were calculated to have phases which had hydrostatic tensile stresses that exceeded the $1 \mathrm{~d}$ tensile strength of the pastes, and all CSA cement pastes experienced expansion.

(g) $\mathrm{AH}_{3}$. The contribution of $\mathrm{AH}_{3}$ to the sum hydrostatic tensile stress developed in CSA cement pastes is reduced by its nanocrystalline nature, which reduces the net crystallisation pressures that it can develop and the range of pores where it can effectively exert pressure.

In summary, this study showed that, according to calculations utilised in prior research, all crystalline hydrates such as ettringite, monosulfate, strätlingite, $\mathrm{CAH}_{10}$ and $\mathrm{AH}_{3}$ may contribute to the total crystallisation pressures that are developed in CSA cement pastes and may contribute to the expansion mechanism. Future work should aim to determine the interfacial free energies and spatial distributions of the crystalline hydrates to better understand how each crystalline hydration product may or may not contribute to cement expansion.

\section{Acknowledgements}

The authors thank Luigi Brunetti, Stephan Geis, Boris Ingold, Daniel Käppeli and Marcel Käppeli for assistance in the laboratory, Josef Kaufmann for assistance with MIP measurements and analysis, Mateusz Wyrzykowski for assistance with ASTM 1698 measurements and analysis, and Rolf Blumer and Lionel Raynaud for further support. In addition, the Innovation and Promotion Agency (CTI) Switzerland (project no. 14623.1 PFIW-IW) and Saint-Gobain Weber AG, Winterthur, Switzerland are acknowledged for their financial support. The stay of Craig W. Hargis at Empa was supported by the EU Marie Curie Action of the People Programme (FP7) within the Co-funding of Regional, National and International Programmes (COFUND).

\section{REFERENCES}

Alvarez-Pinazo G, Cuesta A, Garcia-Mate M et al. (2012) Rietveld quantitative phase analysis of Yeelimite-containing cements. Cement and Concrete Research 42(7): 960-971.

ASTM (2009) ASTM C1698-09: Standard test method for autogenous strain of cement paste and mortar. ASTM International, West Conshohocken, PA, USA.

Barneyback RS and Diamond S (1981) Expression and analysis of pore fluids from hardened cement pastes and mortars. Cement and Concrete Research 11(2): 279-285.

Beretka J, Marroccoli M, Sherman N and Valenti GL (1996) The influence of $\mathrm{C}_{4} \mathrm{~A}_{3}$ s content and W/S ratio on the performance of calcium sulfoaluminate-based cements. Cement and Concrete Research 26(11): 1673-1681.

Bernardo G, Telesca A and Valenti GL (2006) A porosimetric study of calcium sulfoaluminate cement pastes cured at early ages. Cement and Concrete Research 36(6): 1042-1047.

Bernardo G, Buzzi L, Canonico F et al. (2007) Microstructural investigations on hydrated high-performance cements based on calcium sulfoaluminate. In Proceedings of 12th International 
Congress on the Chemistry of Cement, Montreal, Canada (Beaudoin JJ, Makar JM and Raki L (eds)). Cement Association of Canada, Ottawa, ON, Canada. paper W3-11.4.

Bizzozero J, Gosselin C and Scrivener KL (2014) Expansion mechanisms in calcium aluminate and sulfoaluminate systems with calcium sulfate. Cement and Concrete Research 56: 190-202.

Buzzi L, Canonico F, Telesca A and Valenti GL (2010) High-performance and low- $\mathrm{CO}_{2}$ cements based on calcium sulphoaluminate. $Z K G$ International 63(5): 39-45.

Calos NJ, Kennard CHL, Whittaker AK and Davis RL (1995) Structure of calcium aluminate sulfate $\mathrm{Ca}_{4} \mathrm{Al}_{6} \mathrm{O}_{16} \mathrm{~S}$. Journal of Solid State Chemistry 119(1): 1-7.

Capmas A and Ménétrier-Sorrentino D (1989) The effect of temperature on the hydration of calcium aluminate cement. In UNITECR ' 89 , Anaheim, CA, USA (Trostel LJ (ed.)). The American Ceramic Society, Westerville, OH, USA, pp. 1157-1170.

Chaunsali P and Mondal P (2015a) Hydration and early-age expansion of calcium sulfoaluminate cement-based binders: experiments and thermodynamic modeling. Journal of Sustainable Cement-based Materials 6(5): 259-267.

Chaunsali P and Mondal P (2015b) Influence of calcium sulfoaluminate (CSA) cement content on expansion and hydration behavior of various ordinary Portland cement-CSA blends. Journal of the American Ceramic Society 98(8): 2617-2624.

Chaunsali P and Mondal P (2016) Physico-chemical interaction between mineral admixtures and OPC-calcium sulfoaluminate (CSA) cements and its influence on early-age expansion. Cement and Concrete Research 80: 10-20.

Chen IA, Hargis CW and Juenger MCG (2012) Understanding expansion in calcium sulfoaluminate-belite cements. Cement and Concrete Research 42(1): 51-60.

Chitvoranund N, Winnefeld F, Hargis CW, Sinthupinyo S and Lothenbach B (2017) Synthesis and hydration of alite-calcium sulfoaluminate cement. Advances in Cement Research 29(3): 101-111, https://doi.org/10.1680/jadcr.16.00071

Cohen MD (1983) Theories of expansion in sulfoaluminate-type expansive cements: schools of thought. Cement and Concrete Research 13(6): 809-818.

Cohen MD and Richards CW (1982) Effects of the particle sizes of expansive clinker on strength-expansion characteristics of type $\mathrm{K}$ expansive cements. Cement and Concrete Research 12(6): 717-725.

Cuesta A, De La Torre AG, Santacruz I et al. (2017a) Chemistry and mass density of aluminum hydroxide gel in eco-cements by ptychographic X-ray computed tomography. The Journal of Physical Chemistry C 121(5): 3044-3054.

Cuesta A, Zea-Garcia JD, Londono-Zuluaga D et al. (2017b) Synchrotron radiation pair distribution function analysis of gels in cements. Crystals 7(10): 317.

Deng $M$ and Tang M (1994) Formation and expansion of ettringite crystals. Cement and Concrete Research 24(1): 119-126.

Empa (2018) http://www.empa.ch/cemdata (accessed 15/10/2018).

Flatt RJ (2002) Salt damage in porous materials: how high supersaturations are generated. Journal of Crystal Growth 242(3-4): 435-454.

Flatt RJ and Scherer GW (2008) Thermodynamics of crystallization stresses in DEF. Cement and Concrete Research 38(3): 325-336.

Garcia-Mate M, De La Torre AG, Leon-Reina L, Aranda MAG and Santacruz I (2013) Hydration studies of calcium sulfoaluminate cements blended with fly ash. Cement and Concrete Research 54: $12-20$.

Gastaldi D, Canonico F, Capelli L et al. (2011) Hydraulic behaviour of calcium sulfoaluminate cement alone and in mixture with Portland cement. In Proceedings of 13th International Congress on the Chemistry of Cement, Madrid, Spain (Palomo Á, Zaragoza A and
López Agüí JC (eds)). Instituto de Ciencias de la Construcción Eduardo Torroja, Madrid, Spain, paper 412.

Glasser FP and Zhang L (2001) High-performance cement matrices based on calcium sulfoaluminate-belite compositions. Cement and Concrete Research 31(12): 1881-1886.

Hargis CW, Moon J, Lothenbach B et al. (2014) Calcium sulfoaluminate sodalite $\left(\mathrm{Ca}_{4} \mathrm{Al}_{6} \mathrm{O}_{12} \mathrm{SO}_{4}\right)$ crystal structure evaluation and bulk modulus determination. Journal of the American Ceramic Society 97(3): 892-898.

Hargis CW, Telesca A and Monteiro PJM (2014) Calcium sulfoaluminate (ye'elimite) hydration in the presence of gypsum, calcite, and vaterite. Cement and Concrete Research 65: 15-20.

Hummel W, Berner U, Curti E, Pearson FJ and Thoenen T (2002) Nagra/ PSI chemical thermodynamic data base 01/01. Radiochimica Acta 90(9-11): 805-813.

Ioannou S, Reig L, Paine K and Quillin K (2014) Properties of a ternary calcium sulfoaluminate-calcium sulfate-fly ash cement. Cement and Concrete Research 56: 75-83.

Ioannou S, Paine K, Reig L and Quillin K (2015) Performance characteristics of concrete based on a ternary calcium sulfoaluminate-anhydrite-fly ash cement. Cement \& Concrete Composites 55: 196-204.

Jansen D, Spies A, Neubauer J, Ectors D and Goetz-Neunhoeffer F (2017) Studies on the early hydration of two modifications of ye'elimite with gypsum. Cement and Concrete Research 91: 106-116.

Jeong Y, Hargis CW, Chun SC and Moon J (2018) The effect of water and gypsum content on strätlingite formation in calcium sulfoaluminate-belite cement pastes. Construction and Building Materials 166: 712-722.

Kaufmann J (2010) Pore space analysis of cement-based materials by combined Nitrogen sorption - Wood's metal impregnation and multi-cycle mercury intrusion. Cement and Concrete Composites 32(7): 514-522.

Klein A, Karby T and Polivka M (1961) Properties of an expansive cement for chemical prestressing. Journal Proceedings 58(7): $59-62$.

Kulik DA, Wagner T, Dmytrieva SV et al. (2013) GEM-Selektor geochemical modeling package: revised algorithm and GEMS3K numerical kernel for coupled simulation codes. Computational Geosciences 17(1): 1-24.

Kurdowski W and Thiel A (1981) On the role of free calcium oxide in expansive cements. Cement and Concrete Research 11(1): $29-40$.

Le Saout G, Kocaba V and Scrivener K (2011) Application of the Rietveld method to the analysis of anhydrous cement. Cement and Concrete Research 41(2): 133-148.

Lothenbach B, Matschei T, Moschner G and Glasser FP (2008) Thermodynamic modelling of the effect of temperature on the hydration and porosity of Portland cement. Cement and Concrete Research 38(1): 1-18.

Lothenbach B, Pelletier-Chaignat $L$ and Winnefeld F (2012) Stability in the system $\mathrm{CaO}-\mathrm{Al}_{2} \mathrm{O}_{3}-\mathrm{H}_{2} \mathrm{O}$. Cement and Concrete Research 42(12): 1621-1634.

Martin LHJ, Winnefeld F, Müller CJ and Lothenbach B (2015) Contribution of limestone to the hydration of calcium sulfoaluminate cement. Cement \& Concrete Composites 62: 204-211.

Matschei T, Lothenbach B and Glasser FP (2007) Thermodynamic properties of Portland cement hydrates in the system $\mathrm{CaO}-\mathrm{Al}_{2} \mathrm{O}_{3}-\mathrm{SiO}_{2}-\mathrm{CaSO}_{4}-\mathrm{CaCO}_{3}-\mathrm{H}_{2} \mathrm{O}$. Cement and Concrete Research 37(10): 1379-1410.

Mehta PK (1980) Investigations on energy-saving cement. World Cement Technology 11(4): 166-177.

Merkel BJ and Planer-Friederich B (2008) Groundwater Geochemistry A Practical Guide to Modeling of Natural and Contaminated Aquatic Systems. Springer, Berlin, Germany. 
Odler I and Colan-Subauste J (1999) Investigations on cement expansion associated with ettringite formation. Cement and Concrete Research 29(5): 731-735.

Pelletier-Chaignat L, Winnefeld F, Lothenbach B and Müller CJ (2012) Beneficial use of limestone filler with calcium sulphoaluminate cement. Construction and Building Materials 26(1): 619-627.

Pokrovskii VA and Helgeson HC (1995) Thermodynamic properties of aqueous species and the solubilities of minerals at high pressures and temperatures: the system $\mathrm{Al}_{2} \mathrm{O}_{3}-\mathrm{H}_{2} \mathrm{O}-\mathrm{NaCl}$. American Journal of Science 295: 1255-1342.

Sant G, Lothenbach B, Juilland P et al. (2011) The origin of early age expansions induced in cementitious materials containing shrinkage reducing admixtures. Cement and Concrete Research 41(3): 218-229.

Scherer GW (1999) Crystallization in pores. Cement and Concrete Research 29(8): 1347-1358.

Scherer GW (2004) Stress from crystallization of salt. Cement and Concrete Research 34(9): 1613-1624.

Steiger M (2005a) Crystal growth in porous materials - I: the crystallization pressure of large crystals. Journal of Crystal Growth 282(3-4): 455-469.

Steiger M (2005b) Crystal growth in porous materials - II: influence of crystal size on the crystallization pressure. Journal of Crystal Growth 282(3-4): 470-481.

Steiger M (2006) Crystal growth in porous materials: influence of supersaturation and crystal size. In Proceedings of International Conference on Heritage, Weathering and Conservation, Madrid, Spain (Fort R, Alvarez de Buergo M, Gomez-Heras M and
Vazquez-Calvo C (eds)). Taylor \& Francis Group/Balkema, Leiden, the Netherlands, vol. II, pp. 245-251.

Wagner T, Kulik DA, Hingerl FF and Dmytrieva SV (2012) GEM-Selektor geochemical modeling package: TSolMod library and data interface for multicomponent phase models. The Canadian Mineralogist 50(5): 1173-1195.

Winnefeld F and Barlag S (2010) Calorimetric and thermogravimetric study on the influence of calcium sulfate on the hydration of ye'elimite. Journal of Thermal Analysis and Calorimetry 101(3): 949-957.

Winnefeld F and Lothenbach B (2016) Phase equilibria in the system $\mathrm{Ca}_{4} \mathrm{Al}_{6} \mathrm{O}_{12} \mathrm{SO}_{4}-\mathrm{Ca}_{2} \mathrm{SiO}_{4}-\mathrm{CaSO}_{4}-\mathrm{H}_{2} \mathrm{O}$ referring to the hydration of calcium sulfoaluminate cements. RILEM Technical Letters 1: 10-16.

Wyrzykowski M, Hu Z, Ghourchian S, Scrivener K and Lura P (2016) Corrugated tube protocol for autogenous shrinkage measurements: review and statistical assessment. Materials and Structures 50(1): 57.

Xie P and Beaudoin JJ (1992) Mechanism of sulfate expansion. 1. Thermodynamic principle of crystallization pressure. Cement and Concrete Research 22(4): 631-640.

Wang Y, Su M, Yang R and Lui B (1992) A quantitative study of paste microstructures and hydration characters of sulphoaluminate cement. In Proceedings of 9th International Congress on the Chemistry of Cement, New Delhi, India (Mullik AK (ed.)). National Council for Cement and Building Materials (NCB), New Delhi, India, vol. 4, pp. 454-460.

Zivica V (2000) Properties of blended sulfoaluminate belite cement. Construction and Building Materials 14(8): 433-437. 